\title{
Infecções relacionadas à assistência em saúde em unidades de terapia intensiva no Brasil
}

\author{
Infections related to health care in intensive care units in Brazil
}

Infecciones relacionadas con la atención de salud en unidades de cuidados intensivos en Brasil

André Augusto Guerra Gomes ${ }^{1 *}$, Murilo Rodrigues da Silva ${ }^{1}$, Tereza Cristina de Carvalho Souza Garcês ${ }^{1}$, Antonione Santos Bezerra Pinto ${ }^{1}$, Sonia Maria Oliveira de Andrade ${ }^{2}$, Eduarda Rêgo Saraiva ${ }^{1}$, Siana Malena Soares Brito ${ }^{1}$, Dandara dos Santos Gomes Gadelha ${ }^{1}$, Ana Rachel Oliveira de Andrade'.

\section{RESUMO}

Objetivo: Analisar as Infecções relacionadas a assistência em pacientes de Unidades de Terapia Intensiva no Brasil, a fim de traçar um perfil epidemiológico. Métodos: Trata-se de uma revisão de literatura. A busca foi realizada na base de dados Portal Regional Brasileiro da Biblioteca Virtual de Saúde (BVS), compreendendo período de janeiro de 2010 a dezembro de 2019, com os descritores em saúde (DeCS) "Unidade de Terapia Intensiva" e "infecção hospitalar", no Brasil, em todas as línguas. Os artigos que se enquadram nos critérios de exclusão são aqueles que não apresentavam o tema principal, estavam duplicados ou não possuíam acesso livre. Resultados: Dos 32 artigos selecionados, 84.4\% foram publicados em periódicos nacionais. Dentre eles, 68.7\% relataram ter mais indivíduos do sexo masculino, além de uma faixa etária de recém-nascido há 94 anos. Os microorganismos mais presentes foram: Estafilococos coagulase-negativa, Pseudomonas aeruginosa e Staphylococcus aureus. Conclusão: As infecções nosocomiais são frequentes em unidades de terapia intensiva (UTIs), devido ao uso rotineiro de dispositivos invasivos para a manutenção do paciente, além da alta manipulação do mesmo. Os patógenos mais observados nessas localidades fazem parte da microbiota endógena, mas tem se mostrado cada vez mais resistentes devido à utilização de agentes microbianos de maneira desordenada e a falta de capacitação dos profissionais de saúde.

Palavras-chave: Unidade de terapia intensiva, Infecção hospitalar, Brasil.

\section{ABSTRACT}

Objective: Through a systematic review of the literature perform an analysis of infections related to care in patients in intensive care units in Brazil, in order to trace an epidemiological profile. Methods: This is a literature review. A search was carried out in the database of the Brazilian Regional Portal of the Virtual Health Library (VHL), covering the period from January 2010 to December 2019, with the health descriptors (DeCS) "Intensive Care Unit" and "infection hospital" in Brazil, in all languages. Articles that meet the exclusion criteria are those that do not have the main theme, were duplicated or did not have free access. Results: Of the 32 selected articles, $84.4 \%$ were published in national journals. Among them, 68.7\% reported being over male, with the age of a newborn for 94 years. The microorganisms most present were: coagulase-negative staphylococci, Pseudomonas aeruginosa and Staphylococcus aureus. Conclusion: Nosocomial infections are frequent in intensive care units (ICUs), due to the routine use of invasive devices for patient maintenance, in addition to their high manipulation. The most observed pathogens in these locations are part of the endogenous microbiota, but there are if they are increasingly resistant due to the disordered use of microbial agents and a lack of training for health professionals.

Keywords: Intensive care unit, Hospital infection, Brazil.

\footnotetext{
${ }^{1}$ Instituto de Educação Superior do Vale do Parnaíba (IESVAP), Parnaíba - PI.

*E-mail: andre_auggusto@hotmail.com

${ }^{2}$ Instituto Integrado de Saúde - Universidade Federal de Mato Grosso do Sul (INISA/UFMS),

Campo Grande - MS.
} 


\section{RESUMEN}

Objetivo: Realizar, a través de una revisión sistemática de la literatura, un análisis de las Infecciones relacionadas con la atención en pacientes de Unidades de Cuidados Intensivos en Brasil, con el fin de dibujar un perfil epidemiológico. Métodos: Esta es una revisión de la literatura. La búsqueda se realizó en la base de datos de la Biblioteca Regional Brasileña de la Biblioteca Virtual en Salud (BVS), cubriendo el período de enero de 2010 a diciembre de 2019, con los descriptores de salud (DeCS) "Unidad de Cuidados Intensivos" e "infección hospitalaria", en Brasil, en todos los idiomas. Los artículos que cumplen con los criterios de exclusión son aquellos que no tenían el tema principal, estaban duplicados o no tenían acceso libre. Resultados: De los 32 artículos seleccionados, $84.4 \%$ fueron publicados en revistas nacionales. Entre ellos, el $68.7 \%$ reportó tener más individuos masculinos, además de un grupo de 94 años de edad para recién nacidos. Los microorganismos más presentes fueron: estafilococos coagulasa negativos, Pseudomonas aeruginosa y Staphylococcus aureus. Conclusión: Las infecciones nosocomiales son frecuentes en las unidades de cuidados intensivos $(\mathrm{UCl})$, ebido al uso rutinario de dispositivos invasivos para el mantenimiento del paciente, además de su alta manipulación. Los patógenos más observados en estas localidades forman parte de la microbiota endógena, pero los hay si son cada vez más resistentes por el uso desordenado de agentes microbianos y la falta de formación de los profesionales sanitarios.

Palabras clave: Unidad de cuidados intensivos, Infección hospitalaria, Brasil.

\section{INTRODUÇÃO}

Uma infecção nosocomial, também chamada "infecção adquirida no hospital", "infecção hospitalar" ou "Infecção Relacionada a Assistência em Saúde (IRAS)", é definida, de acordo com a Portaria n 2.616 do Ministério da Saúde do Brasil, como aquela que se surge após 72 horas de internação, ou antes, desde que relacionada a procedimentos diagnósticos e/ou terapêuticos realizados com o paciente, assim como após a alta hospitalar ou infecções ocupacionais nos profissionais de saúde (ARAÚJO PL, 2018; Instituto Nacional de Saúde Dr. Ricardo Jorge, 2011.).

As infecções nosocomiais constituem um grave problema de saúde pública mundial e estima-se que, no mundo, quase meio milhão de casos de infecções nosocomiais ocorram a cada ano nas Unidades de Terapia Intensiva (UTIs). No Brasil as IRAS apresentam taxas de incidência de $22,8 \%$ quando comparado aos países desenvolvidos europeus cujas taxas são menores que 9\% (COELHO MS, et al., 2011; COSTA M, et al., 2020).

A causa deve estar nas várias intervenções diagnósticas ou terapêuticas invasivas, tais como o uso frequente de um amplo espectro de antibióticos, presença de doenças subjacentes e ventilação mecânica, cateterismo venoso central, monitoramento invasivo de pressão e cateterismo urinário, bem como internações mais longas e o uso contínuo de desinfetantes e antissépticos, como o álcool em gel. (DERELI N, et al., 2013; REIS LM, et al., 2011).

Com esses procedimentos, o paciente internado vive em constante exposição à sua própria microbiota e a do ambiente hospitalar. A maioria das vezes eles são acometidos por diversas complicações do processo hospitalar, como doenças agudas ou até mesmo complicações de doenças crônicas, nas quais as mais comuns são as infecções hospitalares (MOREIRA JB e SOUZA ICS, 2016; HESPANHOL LAB, et al., 2019).

Outro potencial reservatório de microrganismos, não menos importante, são os jalecos utilizados pelos profissionais de saúde em geral. Esse Equipamento de Proteção Individual (EPI), que tem função primordial de proteger o profissional, se contaminado, pode tornar-se veículo de disseminação de microrganismos sensíveis e resistentes. (MODESTO EM e FERREIRA JNM, 2019).

Diversos são os organismos relacionados a contaminações em ambientes hospitalares e processos de Infecções Relacionados à Assistência à Saúde (IRAS), no entanto, os principais patógenos incluem Staphylococcus aureus resistente à oxacilina (ORSA), Enterococcus sp. resistente à vancomicina (VRE) e, mais recentemente, enterobactérias produtoras de Beta Lactamase de Espectro Estendido (ESBL) e Acinetobacter baumannii resistente à antibióticos carbapenêmicos (ROCHA IV, et al., 2015; BORDIGNON JC e LIMA LR, 2017). 
Dessa forma, há necessidade de se desenvolver estudos que subsidiem a adoção de melhores estratégias para o manejo dos pacientes que forem acometidos por infecções hospitalares, com vistas ao alcance de melhores prognósticos e diminuição da morbimortalidade desses pacientes.

Diante disso, o presente estudo foi desenvolvido com o objetivo de realizar, por meio de uma revisão sistemática da literatura, uma análise das Infecções relacionadas à assistência em pacientes de Unidades de Terapia Intensiva no Brasil, a fim de traçar um perfil epidemiológico.

\section{MÉTODOS}

Trata-se de uma revisão de literatura onde os artigos foram selecionados utilizando dados secundários, onde se procura, na literatura já existente, associar diferentes pesquisas realizadas em torno de um tema em comum, buscando, entre eles, informações com o intuito de se avaliar criticamente a qualidade da sua metodologia, informações e evidências.

A busca foi realizada na base de dados Portal Regional Brasileiro da Biblioteca Virtual de Saúde (BVS) com artigos do tipo: caso-controle, descritivo, coorte, série de casos e relato de caso, compreendendo o período de janeiro de 2010 a dezembro de 2019, utilizando como busca 'qualquer' que 'contém' os descritores em saúde (DeCS) "Unidade de Terapia Intensiva" e "infecção hospitalar", no Brasil, em todas as línguas.

Foram utilizados como critérios de inclusão artigos na língua portuguesa, espanhola e inglesa, com o tema principal a infecção nosocomial em Unidade de Terapia Intensiva brasileiras e o perfil dos patógenos associados a essas infecções. Os artigos que se enquadram nos critérios de exclusão são aqueles que não apresentavam o tema principal, estavam duplicados ou não possuíam acesso livre.

Para a extração de dados, foram primeiramente avaliados os títulos dos artigos, com o intuito de se constatar o foco de cada um deles ou observar duplicidade. Após isso, os resumos dos estudos remanescentes foram analisados para se averiguar seus objetivos, metodologia e resultados. Por fim, o restante dos artigos foi apurado seguindo os critérios de inclusão e exclusão, opor meio de toda sua leitura e análise integral (Figura 1).

Figura 1 - Método de seleção de artigos.

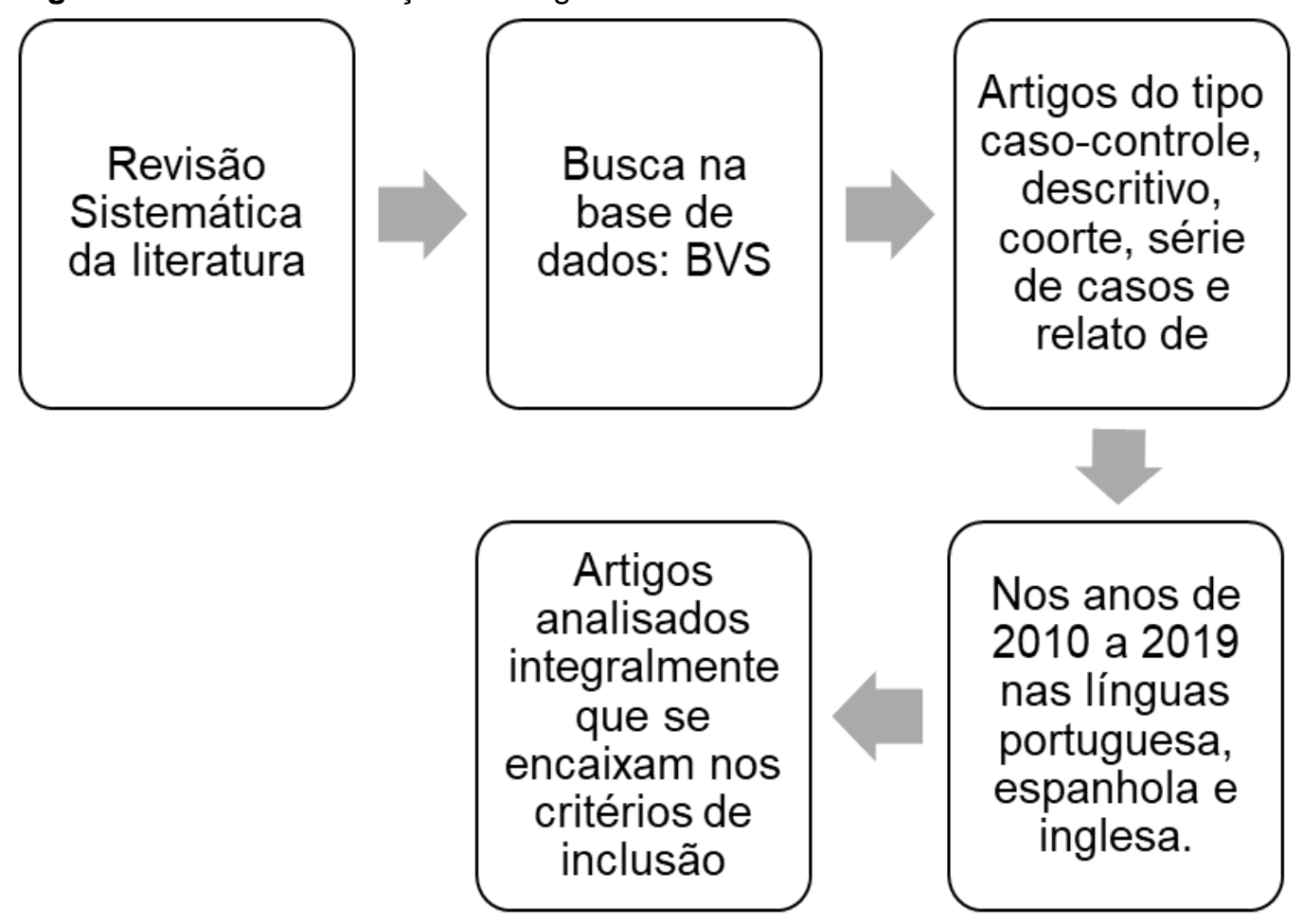

Fonte: Gomes AAG e Silva MR, 2020. 


\section{RESULTADOS}

Foram encontrados 8707 artigos compatíveis com o tema do estudo, os quais estavam disponíveis na base de dados Portal Regional Brasileiro da Biblioteca Virtual de Saúde (BVS). Destes artigos, 137 foram selecionados a partir dos filtros disponíveis na ferramenta de pesquisa da base de dados (Figura 2).

Figura 2 - Processo de seleção dos dados.

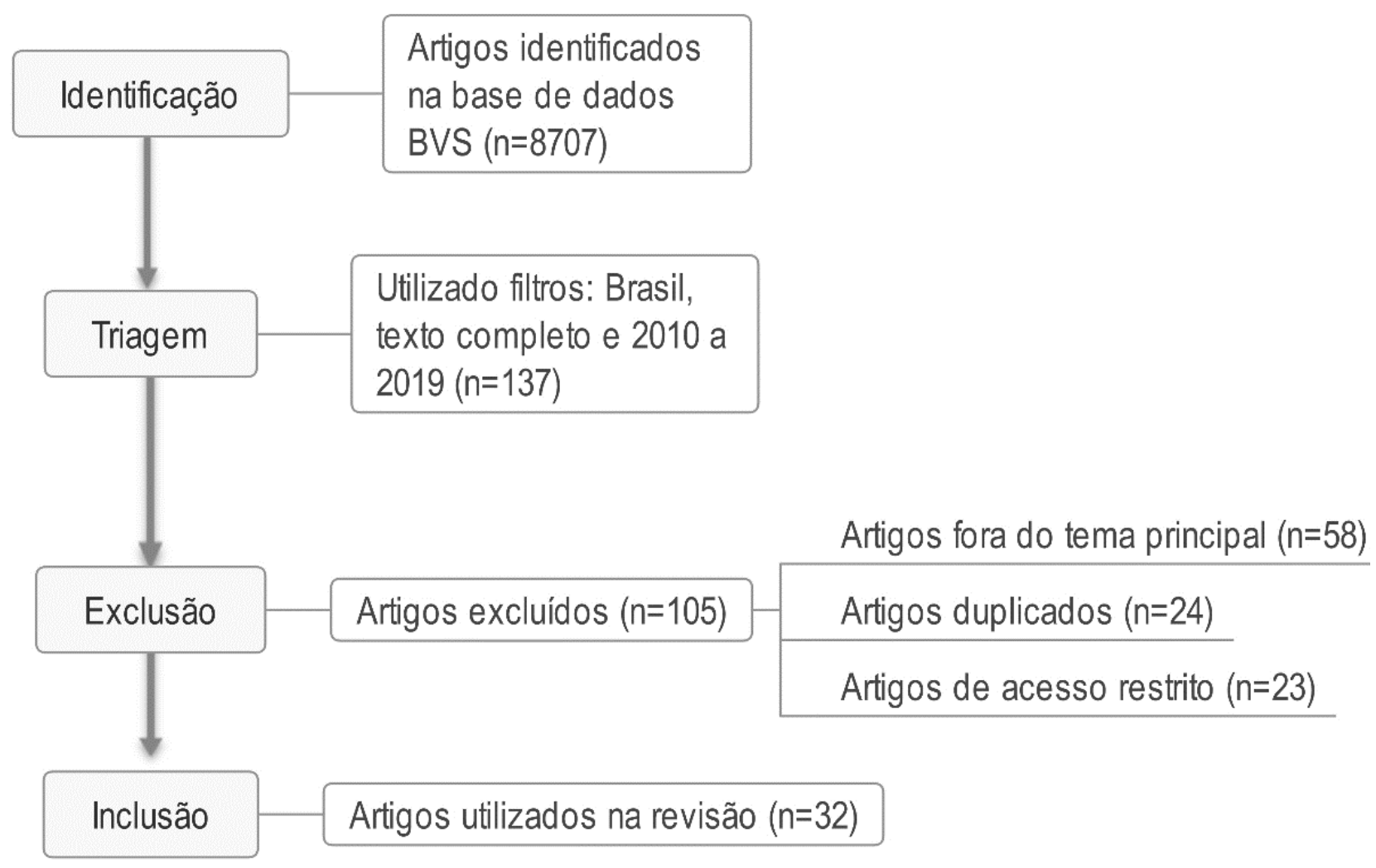

Fonte: Gomes AAG e Silva MR, 2020.

Após leitura dos resumos dos 137 artigos, foram selecionados 32 para compor a revisão de literatura, uma vez que nos outros 105 não constavam os patógenos e/ou perfil dos infectados ou os artigos estavam com acesso restrito ou o artigo estava duplicado e não apresentavam uma visão geral das infecções nosocomiais em pacientes de Unidades de Terapia Intensiva.

Encontram-se sumarizadas as informações colhidas nos 32 estudos selecionados, considerando informações como título do trabalho, ano de publicação, periódicos de publicação, tipo de estudo, local do estudo, tamanho da amostra, faixa etária e sexo mais prevalente dos indivíduos acometidos, patógenos identificados, fatores de risco da população, sítio anatômico acometido, taxa de mortalidade, método diagnóstico da infecção e as condutas frente ao diagnóstico (Quadro 1). 


\section{Revista Eletrônica Acervo Saúde / Electronic Journal Collection Health ISSN 2178-2091}

Quadro 1 - Artigos que compõem a revisão.

\begin{tabular}{|c|c|c|c|c|c|c|c|c|c|c|}
\hline \multicolumn{2}{|c|}{$\begin{array}{l}\text { Ano de publicação/ título } \\
\text { do artigo }\end{array}$} & \multirow{2}{*}{$\begin{array}{c}\text { Tipo de } \\
\text { estudo } \\
\\
\\
\text { Estudo } \\
\text { prospectivo de } \\
\text { coorte } \\
\text { observacional }\end{array}$} & \multirow{2}{*}{$\begin{array}{c}\text { Local do } \\
\text { estudo }\end{array}$} & \multirow{2}{*}{$\begin{array}{c}\begin{array}{c}\text { Tamanho da } \\
\text { amostra/faixa } \\
\text { etária/sexo mais } \\
\text { prevalente }\end{array} \\
\\
\\
\\
279 \text { pacientes (239 } \\
\text { amostras positivas) } \\
\text { / menores de } 3 \\
\text { anos / masculino }\end{array}$} & \multirow{2}{*}{$\begin{array}{c}\begin{array}{c}\text { Patógenos } \\
\text { mais } \\
\text { frequentes }\end{array} \\
\\
\text { Rinovírus, } \\
\text { Vírus sincicial } \\
\text { respiratório, } \\
\text { HCoV }\end{array}$} & \multirow{2}{*}{$\begin{array}{c}\text { Fatores de risco } \\
\text { observados }\end{array}$} & \multirow{2}{*}{$\begin{array}{c}\text { Sítio } \\
\text { anatômico } \\
\\
\text { Infecção do } \\
\text { trato } \\
\text { respiratório }\end{array}$} & \multirow{2}{*}{\begin{tabular}{|c|}
$\begin{array}{c}\text { Taxa de } \\
\text { mortalid } \\
\text { ade }\end{array}$ \\
\\
\\
\\
\\
$.40 \%$ \\
\end{tabular}} & \multirow{2}{*}{$\begin{array}{l}\text { Diagnóstico } \\
\text { laboratorial } \\
\\
\\
\text { Análise de } \\
\text { aspirado } \\
\text { nasofaringeo } \\
\text { por PCR }\end{array}$} & \multirow{2}{*}{$\begin{array}{c}\text { Conduta } \\
\text { medicamentosa } \\
\text { majoritária }\end{array}$} \\
\hline 1 & $\begin{array}{c}\text { 2019/Coronavírus } \\
\text { humano isolado ou em } \\
\text { coinfecção com } \\
\text { rinovírus C é fator de } \\
\text { risco para doença } \\
\text { respiratória grave e } \\
\text { admissão em unidade } \\
\text { de terapia intensiva } \\
\text { pediátrica: estudo de um } \\
\text { ano no Sudeste do } \\
\text { Brasil } \\
\end{array}$ & & & & & & & & & \\
\hline 2 & $\begin{array}{l}2019 / \text { Colistina e } \\
\text { polimixina B para } \\
\text { tratamento de infecções } \\
\text { nosocomiais em } \\
\text { pacientes de unidade de } \\
\text { terapia intensiva: análise } \\
\text { farmacoeconômica }\end{array}$ & $\begin{array}{l}\text { Estudo de } \\
\text { coorte } \\
\text { retrospectivo }\end{array}$ & $\begin{array}{c}\text { UTI } \\
\text { neurocirúrgica, } \\
\text { cardiovascular } \\
\text { e transplante } \\
\text { do Hospital das } \\
\text { Clínicas da } \\
\text { Universidade } \\
\text { de Campinas- } \\
\text { SP }\end{array}$ & $\begin{array}{l}190 \text { pacientes/ } \\
\text { mais de } 18 \text { anos / } \\
\text { masculino }\end{array}$ & $\begin{array}{c}\text { Infecção } \\
\text { causada por } \\
\text { bactérias gram- } \\
\text { negativas }\end{array}$ & Diabetes Mellitus & $\begin{array}{l}\text { Diversos } \\
\text { (pacientes com } \\
\text { ventilação } \\
\text { mecânica, } \\
\text { sepsis, choque } \\
\text { séptico, } \\
\text { infecção do } \\
\text { trato urinário) }\end{array}$ & \begin{tabular}{|c}
$25,29 \%$ \\
(colistina \\
); \\
$33,3 \%$ \\
(polimixi \\
na B)
\end{tabular} & $\begin{array}{l}\text { Análise de } \\
\text { amostras } \\
\text { isoladas do } \\
\text { sítio da } \\
\text { infecção }\end{array}$ & $\begin{array}{c}\text { Uso de colistina e } \\
\text { polimixina } B\end{array}$ \\
\hline 3 & $\begin{array}{l}\text { 2018/ Uma alta taxa de } \\
\text { mortalidade associada a } \\
\text { Acinetobacter baumannii } \\
\text { ST79 multirresistente e } \\
\text { ST25 com OXA-23 em } \\
\text { uma unidade de terapia } \\
\text { intensiva brasileira }\end{array}$ & $\begin{array}{l}\text { Estudo de } \\
\text { caso-controle }\end{array}$ & $\begin{array}{l}\text { Duas UTI de } \\
\text { adultos em um } \\
\text { hospital de } \\
\text { ensino superior } \\
\text { localizado na } \\
\text { cidade de } \\
\text { Dourados, no } \\
\text { Mato Grosso } \\
\text { do Sul, Brasil }\end{array}$ & $\begin{array}{l}275 \text { pacientes/24- } \\
87 \text { anos/ Masculino }\end{array}$ & A. baumannii & $\begin{array}{l}\text { Diabetes mellitus, } \\
\text { hipertensão, doenças } \\
\text { crônicas e sepse }\end{array}$ & $\begin{array}{l}\text { Infecção do } \\
\text { trato } \\
\text { respiratório }\end{array}$ & $34.1 \%$ & $\begin{array}{l}\text { Análise da } \\
\text { secreção } \\
\text { traqueal }\end{array}$ & $\begin{array}{c}\text { Terapia } \\
\text { antimicrobiana por } \\
30 \text { dias: penicilina, } \\
\text { cefalosporinas de } \\
\text { terceira ou quarta } \\
\text { geração, } \\
\text { aminoglicosídeosfl } \\
\text { uoroquinolonas, } \\
\text { amicacina, } \\
\text { tigeciclina, } \\
\text { piperacilina / } \\
\text { tazobactam, } \\
\text { trimetoprim, } \\
\text { carbapenêmicos e } \\
\text { polimixinas. }\end{array}$ \\
\hline
\end{tabular}

REAS / EJCH | Vol.12(11) | e4665 | DOI: https://doi.org/10.25248/reas.e4665.2020 Página 5 de 18 
Revista Eletrônica Acervo Saúde / Electronic Journal Collection Health ISSN 2178-2091

\begin{tabular}{|c|c|c|c|c|c|c|c|c|c|c|}
\hline \multicolumn{2}{|c|}{$\begin{array}{l}\text { Ano de publicação/ título } \\
\text { do artigo }\end{array}$} & \multirow{2}{*}{$\begin{array}{c}\begin{array}{c}\text { Tipo de } \\
\text { estudo }\end{array} \\
\text { Relato de caso }\end{array}$} & \multirow{2}{*}{$\begin{array}{c}\begin{array}{c}\text { Local do } \\
\text { estudo }\end{array} \\
\\
\text { UTI neonatal } \\
\text { do Hospital } \\
\text { Pequeno } \\
\text { Príncipe, } \\
\text { Curitiba, Brasil }\end{array}$} & \multirow{2}{*}{$\begin{array}{c}\text { Tamanho da } \\
\text { amostra/faixa } \\
\text { etária/sexo mais } \\
\text { prevalente }\end{array}$} & \multirow{2}{*}{$\begin{array}{c}\begin{array}{c}\text { Patógenos } \\
\text { mais } \\
\text { frequentes }\end{array} \\
\\
\text { Ralstonia } \\
\text { mannitolilytica }\end{array}$} & \multirow{2}{*}{$\begin{array}{c}\text { Fatores de risco } \\
\text { observados }\end{array}$} & \multirow{2}{*}{$\begin{array}{c}\begin{array}{c}\text { Sítio } \\
\text { anatômico }\end{array} \\
\\
\text { Infecção da } \\
\text { corrente } \\
\text { Sanguínea }\end{array}$} & \multirow{2}{*}{$\begin{array}{c}\begin{array}{c}\text { Taxa de } \\
\text { mortalid } \\
\text { ade }\end{array} \\
\\
\text { Não } \\
\text { definido } \\
\text { no } \\
\text { estudo }\end{array}$} & \multirow{2}{*}{$\begin{array}{l}\text { Diagnóstico } \\
\text { laboratorial } \\
\\
\text { Hemocultura }\end{array}$} & \multirow{2}{*}{$\begin{array}{c}\begin{array}{c}\text { Conduta } \\
\text { medicamentosa } \\
\text { majoritária }\end{array} \\
\\
\text { Meropenem, } \\
\text { vancomicina e } \\
\text { cefepima }\end{array}$} \\
\hline 4 & $\begin{array}{l}\text { 2018/ Bacteremia por } \\
\text { Ralstonia mannitolilytica } \\
\text { em unidade de terapia } \\
\text { intensiva neonatal }\end{array}$ & & & & & & & & & \\
\hline 5 & $\begin{array}{l}\text { 2018/ Prevalência de } \\
\text { infecção relacionada à } \\
\text { saúde em pacientes } \\
\text { internados em unidade } \\
\text { de terapia intensiva }\end{array}$ & $\begin{array}{l}\text { Estudo } \\
\text { descritivo, } \\
\text { retrospectivo, } \\
\text { de abordagem } \\
\text { quantitativa }\end{array}$ & $\begin{array}{l}\text { Hospital } \\
\text { universitário, } \\
\text { localizado na } \\
\text { cidade de } \\
\text { Natal-RN, } \\
\text { Brasil }\end{array}$ & $\begin{array}{l}33 \text { pacientes/ 18- } \\
92 \text { anos/ feminine }\end{array}$ & $\begin{array}{c}\text { Acinetobacter } \\
\text { sp, } \\
\text { pseudômonas } \\
\text { sp., Klebsiella } \\
\text { sp.. }\end{array}$ & $\begin{array}{c}\text { Tempo de permanência } \\
\text { na UTI }\end{array}$ & $\begin{array}{c}\text { Infecção do } \\
\text { trato } \\
\text { respiratório, } \\
\text { trato urinário, } \\
\text { corrente } \\
\text { sanguínea, } \\
\text { cateter } \\
\text { vascular, } \\
\text { sistema } \\
\text { nervoso. } \\
\end{array}$ & $42,4 \%$ & $\begin{array}{l}\text { Cultura de } \\
\text { material } \\
\text { biológico }\end{array}$ & $\begin{array}{l}\text { Estudo de } \\
\text { resistência }\end{array}$ \\
\hline 6 & $\begin{array}{l}\text { 2018/ Altas taxas de } \\
\text { colonização por } \\
\text { Staphylococcus aureus } \\
\text { resistente à meticilina } \\
\text { em uma unidade de } \\
\text { terapia intensiva } \\
\text { brasileira }\end{array}$ & $\begin{array}{l}\text { Estudo } \\
\text { transversal }\end{array}$ & UTI Brasileira & $\begin{array}{l}110 \text { pacientes/ } \\
\text { mais de } 60 \text { anos/ } \\
\text { feminine }\end{array}$ & $\begin{array}{c}\text { Staphylococcus } \\
\text { aureus } \\
\text { Resistente à } \\
\text { Meticilina }\end{array}$ & Não definido no estudo & $\begin{array}{l}\text { Infecção do } \\
\text { trato } \\
\text { respiratório }\end{array}$ & $\begin{array}{c}\text { Não } \\
\text { definido } \\
\text { no } \\
\text { estudo }\end{array}$ & $\begin{array}{l}\text { Cultura de } \\
\text { orofaringe e no } \\
\text { local de } \\
\text { inserção do } \\
\text { cateter venoso } \\
\text { central }\end{array}$ & $\begin{array}{l}\text { Estudo de } \\
\text { resistência }\end{array}$ \\
\hline 7 & $\begin{array}{l}\text { 2017/ Fatores de risco } \\
\text { para mortalidade na } \\
\text { traqueobronquite } \\
\text { associada à ventilação } \\
\text { mecânica: um estudo } \\
\text { caso-controle }\end{array}$ & $\begin{array}{l}\text { Estudo caso- } \\
\text { controle }\end{array}$ & $\begin{array}{l}\text { UTI médico- } \\
\text { cirúrgica em } \\
\text { um hospital } \\
\text { terciário de São } \\
\text { Paulo. }\end{array}$ & $\begin{array}{l}394 \text { pacientes/24- } \\
94 \text { anos/ masculino }\end{array}$ & $\begin{array}{l}P . \text { aeruginosa; } \\
\text { K. pneumoniae }\end{array}$ & $\begin{array}{l}\text { Doença pulmonar, } \\
\text { paciente cirúrgico, } \\
\text { doença intestinal }\end{array}$ & $\begin{array}{l}\text { Infecção do } \\
\text { trato } \\
\text { respiratório }\end{array}$ & $42.5 \%$ & $\begin{array}{l}\text { Cultura } \\
\text { quantitativa do } \\
\text { aspirado } \\
\text { traqueal ou } \\
\text { espécimes de } \\
\text { broncoscopia }\end{array}$ & $\begin{array}{l}\text { Estudo de fatores } \\
\text { de risco }\end{array}$ \\
\hline
\end{tabular}

REAS / EJCH | Vol.12(11) | e4665 | DOI: https://doi.org/10.25248/reas.e4665.2020 Página 6 de 18 
Revista Eletrônica Acervo Saúde / Electronic Journal Collection Health ISSN 2178-2091

\begin{tabular}{|c|c|c|c|c|c|c|c|c|c|c|}
\hline \multicolumn{2}{|c|}{$\begin{array}{l}\text { Ano de publicação/ título } \\
\text { do artigo }\end{array}$} & \multirow{2}{*}{\begin{tabular}{c|}
$\begin{array}{c}\text { Tipo de } \\
\text { estudo }\end{array}$ \\
$\begin{array}{c}\text { Não definido no } \\
\text { estudo }\end{array}$
\end{tabular}} & \multirow{2}{*}{$\begin{array}{c}\begin{array}{c}\text { Local do } \\
\text { estudo }\end{array} \\
\\
\text { UTI do Hospital } \\
\text { Escola filiado a } \\
\text { Universidade } \\
\text { Federal de } \\
\text { Minas Gerais }\end{array}$} & \multirow{2}{*}{$\begin{array}{c}\begin{array}{c}\text { Tamanho da } \\
\text { amostra/faixa } \\
\text { etária/sexo mais } \\
\text { prevalente }\end{array} \\
\\
867 \text { pacientes/ } \\
\text { mais de } 18 \text { anos/ } \\
\text { masculino }\end{array}$} & \multirow{2}{*}{$\begin{array}{c}\begin{array}{c}\text { Patógenos } \\
\text { mais } \\
\text { frequentes }\end{array} \\
\text { A. baumannii }\end{array}$} & \multirow{2}{*}{$\begin{array}{c}\begin{array}{c}\text { Fatores de risco } \\
\text { observados }\end{array} \\
\\
\text { Diabetes Mellitus, uso } \\
\text { prévio de mecanismos } \\
\text { invasivos e de terapia } \\
\text { antimicrobiana }\end{array}$} & \multirow{2}{*}{ 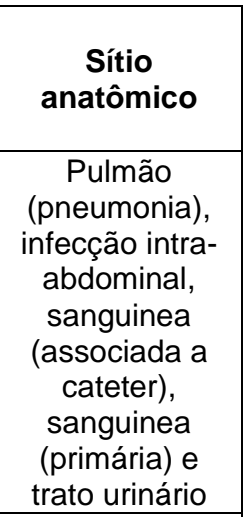 } & \multirow{2}{*}{\begin{tabular}{|c|}
$\begin{array}{c}\text { Taxa de } \\
\text { mortalid } \\
\text { ade }\end{array}$ \\
\\
\\
\\
$59 \%$ \\
\end{tabular}} & \multirow{2}{*}{$\begin{array}{c}\text { Diagnóstico } \\
\text { laboratorial } \\
\\
\text { Cultura }\end{array}$} & \multirow{2}{*}{$\begin{array}{c}\begin{array}{c}\text { Conduta } \\
\text { medicamentosa } \\
\text { majoritária }\end{array} \\
\\
\text { Estudo descritivo } \\
\text { sobre colonização } \\
\text { ou infecção por } \\
\text { CRAb }\end{array}$} \\
\hline 8 & $\begin{array}{c}\text { 2016/ Características } \\
\text { clínicas e } \\
\text { microbiológicas de } \\
\text { Acinetobacter baumannii } \\
\text { produtores de OXA-23 e } \\
\text { OXA-143 em pacientes } \\
\text { de UTI em um hospital } \\
\text { universitário, Brasil }\end{array}$ & & & & & & & & & \\
\hline 9 & \begin{tabular}{|c|}
$2016 /$ Surto de \\
candidemia causado por \\
cepas de Candida \\
parapsilosis resistentes \\
ao fluconazol em \\
unidade de terapia \\
intensiva \\
\end{tabular} & $\begin{array}{l}\text { Estudo } \\
\text { transversal }\end{array}$ & $\begin{array}{c}\text { Não definido no } \\
\text { estudo }\end{array}$ & $\begin{array}{c}40 \text { pacientes } \\
\text { críticos com } \\
\text { candidemia/ } 23-91 \\
\text { anos/ feminino }\end{array}$ & C. parapsilosis & $\begin{array}{l}\text { Histórico de câncer, } \\
\text { doença pulmonar, } \\
\text { doença cardíaca, } \\
\text { Diabetes Mellitus ou } \\
\text { falência renal }\end{array}$ & $\begin{array}{c}\text { Não definido no } \\
\text { estudo }\end{array}$ & $45 \%$ & $\begin{array}{l}\text { PCR tempo } \\
\text { real, teste de } \\
\text { susceptibilidad } \\
\text { e anti fúngica } \\
\text { (in vitro) }\end{array}$ & $\begin{array}{c}\text { Caracterização de } \\
\text { surto por } \\
\text { resistência }\end{array}$ \\
\hline 10 & $\begin{array}{c}\text { 2016/ Características } \\
\text { clínicas e } \\
\text { microbiológicas das } \\
\text { infecções causadas por } \\
\text { Pseudomonas } \\
\text { aeruginosa em } \\
\text { pacientes internados em } \\
\text { unidades de terapia } \\
\text { intensiva }\end{array}$ & $\begin{array}{l}\text { Estudo de } \\
\text { coorte } \\
\text { retrospectivo }\end{array}$ & $\begin{array}{l}\text { UTI adulto, } \\
\text { pediátrica e } \\
\text { neonatal em } \\
\text { um hospital de } \\
\text { ensino em } \\
\text { Belém, Pará, } \\
\text { Brasil. }\end{array}$ & $\begin{array}{l}54 \text { pacientes/ } \\
\text { todas idades/ } \\
\text { feminino }\end{array}$ & $P$. aeruginosa & Não definido no estudo & $\begin{array}{l}\text { Infecção: } \\
\text { pulmonar, da } \\
\text { corrente } \\
\text { sanguínea, } \\
\text { trato urinário }\end{array}$ & $70 \%$ & Método CLSI & $\begin{array}{l}\text { Estudo de } \\
\text { multidroga- } \\
\text { resistência }\end{array}$ \\
\hline 11 & $\begin{array}{l}\text { 2015/ Sepse tardia em } \\
\text { recém-nascidos: } \\
\text { epidemiologia e efeito } \\
\text { de um pacote para } \\
\text { prevenir infecções de } \\
\text { corrente sanguínea } \\
\text { associadas a cateter } \\
\text { central na unidade de } \\
\text { terapia intensiva } \\
\text { neonatal }\end{array}$ & $\begin{array}{c}\text { Estudo } \\
\text { prospectivo de } \\
\text { coorte } \\
\text { intervencionista }\end{array}$ & \begin{tabular}{|} 
UTIN terciária \\
do Hospital das \\
Clínicas da \\
cidade de \\
Uberlândia-MG
\end{tabular} & $\begin{array}{c}112 \text { pacientes/ } \\
\text { recém-nascido/ } \\
\text { não definidos no } \\
\text { estudo }\end{array}$ & $\begin{array}{l}\text { S.epidermidis; } \\
\text { S. aureus }\end{array}$ & $\begin{array}{c}\text { Idade gestacional }<37 \\
\text { semanas, peso ao } \\
\text { nascer }<1500 \mathrm{~g} \text {, uso de } \\
\text { CVC, nutrição parenteral } \\
\text { e ventilação mecânica }\end{array}$ & $\begin{array}{c}\text { Não definido no } \\
\text { estudo }\end{array}$ & $\begin{array}{c}\text { Não } \\
\text { definido } \\
\text { no } \\
\text { estudo }\end{array}$ & $\begin{array}{l}\text { Cultura } \\
\text { (amostras } \\
\text { sangue) }\end{array}$ & $\begin{array}{l}\text { Comparação pré e } \\
\text { pós-implantação } \\
\text { de protocolo de } \\
\text { prevenção }\end{array}$ \\
\hline
\end{tabular}

REAS / EJCH | Vol.12(11) | e4665 | DOI: https://doi.org/10.25248/reas.e4665.2020 Página $\mathbf{7}$ de 18 
Revista Eletrônica Acervo Saúde / Electronic Journal Collection Health ISSN 2178-2091

\begin{tabular}{|c|c|c|c|c|c|c|c|c|c|c|}
\hline \multicolumn{2}{|c|}{$\begin{array}{l}\text { Ano de publicação/ título } \\
\text { do artigo }\end{array}$} & \multirow{2}{*}{\begin{tabular}{c|} 
Tipo de \\
estudo \\
\\
Estudo \\
$\begin{array}{c}\text { observacional } \\
\text { transversal }\end{array}$
\end{tabular}} & \multirow{2}{*}{$\begin{array}{c}\begin{array}{c}\text { Local do } \\
\text { estudo }\end{array} \\
\text { UTI do Hospital } \\
\text { São } 41 \\
\text { Francisco de } \\
\text { Assis, em Belo } \\
\text { Horizonte, } \\
\text { Minas Gerais, } \\
\text { Brasil. } \\
\end{array}$} & \multirow{2}{*}{$\begin{array}{c}\text { Tamanho da } \\
\text { amostra/faixa } \\
\text { etária/sexo mais } \\
\text { prevalente }\end{array}$} & \multirow{2}{*}{$\begin{array}{c}\begin{array}{c}\text { Patógenos } \\
\text { mais } \\
\text { frequentes }\end{array} \\
\text { P. gingivalis e } \\
\text { T. denticola }\end{array}$} & \multirow{2}{*}{$\begin{array}{c}\text { Fatores de risco } \\
\text { observados } \\
\\
\text { Doenças } \\
\text { cardiovasculares } \\
\text { diabetes, doenças } \\
\text { respiratórias }\end{array}$} & \multirow{2}{*}{\begin{tabular}{|c|}
$\begin{array}{c}\text { Sítio } \\
\text { anatômico }\end{array}$ \\
$\begin{array}{c}\text { Não definido no } \\
\text { estudo }\end{array}$
\end{tabular}} & \multirow{2}{*}{\begin{tabular}{|c|}
$\begin{array}{c}\text { Taxa de } \\
\text { mortalid } \\
\text { ade }\end{array}$ \\
\\
Não \\
definido \\
no \\
estudo
\end{tabular}} & \multirow{2}{*}{$\begin{array}{l}\begin{array}{l}\text { Diagnóstico } \\
\text { laboratorial }\end{array} \\
\\
\begin{array}{l}\text { Periodontogra } \\
\text { ma }\end{array} \\
\end{array}$} & \multirow{2}{*}{\begin{tabular}{|c|}
$\begin{array}{c}\text { Conduta } \\
\text { medicamentosa } \\
\text { majoritária }\end{array}$ \\
$\begin{array}{c}\text { Não definido no } \\
\text { estudo }\end{array}$ \\
\end{tabular}} \\
\hline 12 & $\begin{array}{c}\text { 2015/ Condição } \\
\text { periodontal de } \\
\text { indivíduos internados } \\
\text { em unidade de terapia } \\
\text { intensiva: perspectiva } \\
\text { clínica, epidemiológica e } \\
\text { microbiológica }\end{array}$ & & & & & & & & & \\
\hline 13 & $\begin{array}{c}\text { 2014/ Impacto das } \\
\text { infecções hospitalares } \\
\text { na evolução dos } \\
\text { pacientes submetidos à } \\
\text { cirurgia cardíaca na } \\
\text { Santa Casa de } \\
\text { Misericórdia de Marília }\end{array}$ & $\begin{array}{l}\text { Estudo de } \\
\text { coorte } \\
\text { retrospectivo }\end{array}$ & $\begin{array}{l}\text { UTI da Santa } \\
\text { Casa de } \\
\text { Misericórdia de } \\
\text { Marília. }\end{array}$ & $\begin{array}{l}2060 \text { pacientes. } \\
351 \text { com infecções } \\
\text { hospitalares (277 } \\
\text { infecções não } \\
\text { cirúrgicas) / idade } \\
\text { média de } 58 \text { anos/ } \\
\text { masculino }\end{array}$ & $\begin{array}{c}\text { Klebsiella } \\
\text { pneumoniae }\end{array}$ & $\begin{array}{l}\text { Infarto agudo do } \\
\text { miocárdio prévio, } \\
\text { hipertensão, } \\
\text { dislipidemia, diabetes } \\
\text { mellitus, tabagismo }\end{array}$ & \begin{tabular}{|} 
Infecção de: \\
sítio cirúrgico, \\
trato urinário, \\
pulmonar \\
(pneumonia \\
associada à \\
ventilação), \\
traqueobronquit \\
e, sanguinea \\
(primária) e \\
cateter vascular
\end{tabular} & $6.4 \%$ & $\begin{array}{l}\text { Dados } \\
\text { secundários - } \\
\text { prontuários }\end{array}$ & $\begin{array}{l}\text { Estudo sobre taxa } \\
\text { de infecção }\end{array}$ \\
\hline 14 & $\begin{array}{c}2014 / \text { Infecções } \\
\text { hospitalares em unidade } \\
\text { de terapia intensiva } \\
\text { neonatal durante } 16 \\
\text { anos: } 1997-2012\end{array}$ & $\begin{array}{l}\text { Estudo } \\
\text { descritivo de } \\
\text { corte } \\
\text { transversal }\end{array}$ & $\begin{array}{l}\text { Hospital } \\
\text { Médico da } \\
\text { Universidade } \\
\text { Federal de } \\
\text { Uberlândia }\end{array}$ & $\begin{array}{c}4615 \text { pacientes/ } \\
\text { neonatal/ não } \\
\text { definido no estudo }\end{array}$ & $\begin{array}{c}\text { Estafilococo } \\
\text { coagulase- } \\
\text { negativa, S. } \\
\text { aureus, } \\
\text { enterococcus, } \\
\text { enterobacter, } \\
\text { K. pneumoniae, } \\
\text { S. marcescens, } \\
\text { P. aeruginosa }\end{array}$ & $\begin{array}{l}\text { Cateter venoso central, } \\
\text { ventilador mecânico }\end{array}$ & $\begin{array}{c}\text { Infecção } \\
\text { primária da } \\
\text { corrente } \\
\text { sanguínea, } \\
\text { conjuntivite, } \\
\text { infecção do } \\
\text { trato urinário, } \\
\text { pneumonia, } \\
\text { enterocolite } \\
\text { necrosante } \\
\end{array}$ & $9.1 \%$ & Hemocultura & $\begin{array}{l}\text { Oxacilina, } \\
\text { vancomicina }\end{array}$ \\
\hline 15 & $\begin{array}{l}\text { 2013/ Epidemiologia } \\
\text { molecular do portador } \\
\text { de Staphylococcus } \\
\text { coagulase-negativa em } \\
\text { neonatos internados em } \\
\text { unidade de terapia } \\
\text { intensiva no Brasil }\end{array}$ & $\begin{array}{c}\text { Foi avaliado o } \\
\text { transporte do } \\
\text { CoNS na } \\
\text { admissão e alta } \\
\text { entre os recém- } \\
\text { nascidos } \\
\text { internados em } \\
\text { uma UTIN }\end{array}$ & $\begin{array}{l}\text { UTI neonatal } \\
\text { do Brasil }\end{array}$ & $\begin{array}{c}392 \text { pacientes/ } \\
\text { neonatos/ } \\
\text { masculino }\end{array}$ & $\begin{array}{l}\text { S. haemolyticus } \\
\text { (S. coagulase- } \\
\text { negativo); } S \text {. } \\
\text { epidermidis }\end{array}$ & $\begin{array}{l}\text { Tempo prolongado de } \\
\text { internação }\end{array}$ & $\begin{array}{l}\text { Não definido no } \\
\text { estudo }\end{array}$ & $\begin{array}{c}\text { Não } \\
\text { definido } \\
\text { no } \\
\text { estudo }\end{array}$ & $\begin{array}{l}\text { Teste } \\
\text { molecular }\end{array}$ & $\begin{array}{l}\text { Estudo com foco } \\
\text { em resistência }\end{array}$ \\
\hline
\end{tabular}

REAS / EJCH | Vol.12(11) | e4665 | DOI: https://doi.org/10.25248/reas.e4665.2020 Página 8 de 18 
Revista Eletrônica Acervo Saúde / Electronic Journal Collection Health ISSN 2178-2091

\begin{tabular}{|c|c|c|c|c|c|c|c|c|c|c|}
\hline \multicolumn{2}{|c|}{$\begin{array}{l}\text { Ano de publicação/ título } \\
\text { do artigo }\end{array}$} & \multirow{2}{*}{$\begin{array}{c}\text { Tipo de } \\
\text { estudo } \\
\\
\\
\text { Estudo de } \\
\text { coorte }\end{array}$} & \multirow{2}{*}{$\begin{array}{c}\begin{array}{c}\text { Local do } \\
\text { estudo }\end{array} \\
\\
\text { Brasil, várias } \\
\text { UTI }\end{array}$} & \multirow{2}{*}{$\begin{array}{c}\begin{array}{c}\text { Tamanho da } \\
\text { amostra/faixa } \\
\text { etária/sexo mais } \\
\text { prevalente }\end{array} \\
\\
2563,342 \\
\text { infectados/ idade } \\
\text { média de } 4,7 \text { anos/ } \\
\text { masculino }\end{array}$} & \multirow{2}{*}{$\begin{array}{c}\begin{array}{c}\text { Patógenos } \\
\text { mais } \\
\text { frequentes }\end{array} \\
\\
\text { Staphylococcus } \\
\text { Coagulase } \\
\text { Negativo; } \\
\text { Klebsiella } \\
\text { species; } S . \\
\text { aureus }\end{array}$} & \multirow{2}{*}{$\begin{array}{c}\begin{array}{c}\text { Fatores de risco } \\
\text { observados }\end{array} \\
\\
\text { Uso de cateter venoso } \\
\text { central, ventilação } \\
\text { mecânica }\end{array}$} & \multirow{2}{*}{$\begin{array}{c}\begin{array}{c}\text { Sítio } \\
\text { anatômico }\end{array} \\
\\
\text { Infecção de } \\
\text { Corrente } \\
\text { Sanguínea, }\end{array}$} & \multirow{2}{*}{\begin{tabular}{|c|}
$\begin{array}{c}\text { Taxa de } \\
\text { mortalid } \\
\text { ade }\end{array}$ \\
\\
\\
\\
$21,60 \%$ \\
\end{tabular}} & \multirow{2}{*}{$\begin{array}{c}\text { Diagnóstico } \\
\text { laboratorial } \\
\\
\text { Hemocultura - } \\
\text { testes } \\
\text { moleculares }\end{array}$} & \multirow{2}{*}{$\begin{array}{c}\begin{array}{c}\text { Conduta } \\
\text { medicamentosa } \\
\text { majoritária }\end{array} \\
\text { Methicilina, } \\
\text { cefazolin, } \\
\text { ciprofloxacina, } \\
\text { clindamicina, } \\
\text { gentamicina } \\
\text { (resistência). } \\
\text { Vancomicina, } \\
\text { telcoplanina, } \\
\text { linezolide (sem } \\
\text { resistência) }\end{array}$} \\
\hline 16 & $\begin{array}{c}2013 / \text { Infecções } \\
\text { nosocomiais da corrente } \\
\text { sanguínea em pacientes } \\
\text { pediátricos brasileiros: } \\
\text { microbiologia, } \\
\text { epidemiologia e } \\
\text { características clínicas }\end{array}$ & & & & & & & & & \\
\hline 17 & $\begin{array}{c}2013 / \text { Infecções } \\
\text { relacionadas à } \\
\text { assistência a saúde } \\
\text { baseada em critérios } \\
\text { internacionais, realizada } \\
\text { em unidade neonatal de } \\
\text { cuidados progressivos } \\
\text { de referência de Belo } \\
\text { Horizonte, MG }\end{array}$ & $\begin{array}{l}\text { Estudo } \\
\text { descritivo }\end{array}$ & $\begin{array}{c}\text { Belo Horizonte, } \\
\text { MG }\end{array}$ & $\begin{array}{l}325 \text { pacientes/ } \\
\text { recém-nascido/ } \\
\text { não definido no } \\
\text { estudo }\end{array}$ & $\begin{array}{c}\text { S. coagulase } \\
\text { negativo; } S \text {. } \\
\text { haemolyticus;S. } \\
\text { aureus }\end{array}$ & $\begin{array}{c}\text { Baixo peso ao } \\
\text { nascimento e uso de } \\
\text { dispositivos invasivos } \\
\text { (cateter venoso central e } \\
\text { cateter umbilical }\end{array}$ & $\begin{array}{l}\text { Sepse clínica } \\
\text { (infecção de } \\
\text { corrente } \\
\text { sanguinea) }\end{array}$ & $4,29 \%$ & Hemocultura & $\begin{array}{c}\text { Todas as amostras } \\
\text { de S. coagulase } \\
\text { negativo foram } \\
\text { sensíveis à } \\
\text { vancomicina }\end{array}$ \\
\hline 18 & $\begin{array}{l}\text { 2013/ Caracterização } \\
\text { das infecções } \\
\text { relacionadas à } \\
\text { assistência à saúde em } \\
\text { uma unidade de terapia } \\
\text { intensiva neonatal }\end{array}$ & $\begin{array}{l}\text { Estudo } \\
\text { descritivo, } \\
\text { quantitativo, } \\
\text { retrospectivo }\end{array}$ & Natal-RN & $\begin{array}{l}100 \text { casos/ recém- } \\
\text { nascido/ masculino }\end{array}$ & $\begin{array}{c}\text { Pseudomonas } \\
\text { aeruginosa e } \\
\text { Staphylococcus } \\
\text { coagulase- } \\
\text { negativo }\end{array}$ & $\begin{array}{c}\text { Baixo peso ao nascer; } \\
\text { prematuridade; grau de } \\
\text { desenvolvimento } \\
\text { imunológico; gravidade } \\
\text { da doença subjacente; } \\
\text { período de } \\
\text { hospitalização e uso de } \\
\text { procedimentos invasivos }\end{array}$ & $\begin{array}{l}\text { Infecção de } \\
\text { Corrente } \\
\text { Sanguínea }\end{array}$ & $\begin{array}{c}\text { Não } \\
\text { definido } \\
\text { no } \\
\text { estudo }\end{array}$ & $\begin{array}{c}\text { Critérios } \\
\text { clínicos e } \\
\text { laboratoriais } \\
\text { com } \\
\text { hemoculturas }\end{array}$ & $\begin{array}{c}\text { Não definido no } \\
\text { estudo }\end{array}$ \\
\hline 19 & $\begin{array}{c}\text { 2013/ Vigilância ativa } \\
\text { para determinar o } \\
\text { impacto da resistência à } \\
\text { meticilina na } \\
\text { mortalidade em } \\
\text { pacientes com } \\
\text { bacteremia e as } \\
\text { influências do uso de } \\
\text { antibióticos no } \\
\text { desenvolvimento de } \\
\text { infecção por MRSA }\end{array}$ & $\begin{array}{c}\text { Estudo } \\
\text { retrospectivo } \\
\text { de controle de } \\
\text { caso, } \\
\text { epidemiológico }\end{array}$ & Uberlândia-MG & $\begin{array}{c}45 \text { pacientes/ } \\
\text { idade média de } \\
48,3 \text { anos/ } \\
\text { masculino }\end{array}$ & $\begin{array}{l}\text { Staphylococcus } \\
\quad \text { aureus } \\
\text { resistente à } \\
\text { meticilina e } \\
\text { Staphylococcus } \\
\text { aureus sensível } \\
\text { à meticilina }\end{array}$ & $\begin{array}{c}\text { Tempo de internação; } \\
\text { uso de cateter venoso } \\
\text { central (CVC); uso de } \\
\text { cateter urinário; sonda } \\
\text { nasogástrica; nutrição } \\
\text { parenteral; } \\
\text { traqueostomia; } \\
\text { ventilação mecânica; e } \\
\text { admintração prévia de } \\
\text { antibióticos. } \\
\end{array}$ & Sepse & $66 \%$ & Hemocultura & $\begin{array}{l}\text { O estudo associou } \\
\text { ao uso de } \\
\text { cefalosporinas de } \\
3^{\underline{a}} \text { e } 4^{\underline{a}} \text { geração, } \\
\text { carbapenêmicos e } \\
\text { vancomicina }\end{array}$ \\
\hline
\end{tabular}

REAS / EJCH | Vol.12(11) | e4665 | DOI: https://doi.org/10.25248/reas.e4665.2020 Página 9 de 18 
Revista Eletrônica Acervo Saúde / Electronic Journal Collection Health ISSN 2178-2091

\begin{tabular}{|c|c|c|c|c|c|c|c|c|c|c|}
\hline \multicolumn{2}{|c|}{$\begin{array}{l}\text { Ano de publicação/ título } \\
\text { do artigo }\end{array}$} & \multirow{2}{*}{$\begin{array}{c}\begin{array}{c}\text { Tipo de } \\
\text { estudo }\end{array} \\
\\
\text { Estudo coorte } \\
\text { prospectivo }\end{array}$} & \multirow{2}{*}{$\begin{array}{c}\begin{array}{c}\text { Local do } \\
\text { estudo }\end{array} \\
\text { São Paulo-SP }\end{array}$} & \multirow{2}{*}{$\begin{array}{c}\text { Tamanho da } \\
\text { amostra/faixa } \\
\text { etária/sexo mais } \\
\text { prevalente }\end{array}$} & \multirow{2}{*}{$\begin{array}{c}\begin{array}{c}\text { Patógenos } \\
\text { mais } \\
\text { frequentes }\end{array} \\
\\
\text { Acinetobacter } \\
\text { spp } \\
\text { multiresistente } \\
\text { e } \\
\text { Pseudomonas } \\
\text { aeruginosa } \\
\text { resistente a } \\
\text { carbapenem }\end{array}$} & \multirow{2}{*}{$\begin{array}{c}\begin{array}{c}\text { Fatores de risco } \\
\text { observados }\end{array} \\
\\
\text { O escore APACHE II, } \\
\text { pressão de colonização } \\
\text { na UTI de neurologia na } \\
\text { semana anterior a um } \\
\text { desfecho e sexo } \\
\text { masculino. }\end{array}$} & \multirow{2}{*}{$\begin{array}{c}\begin{array}{c}\text { Sítio } \\
\text { anatômico }\end{array} \\
\begin{array}{c}\text { Orofaringe e } \\
\text { retal }\end{array}\end{array}$} & \multirow{2}{*}{$\begin{array}{c}\begin{array}{c}\text { Taxa de } \\
\text { mortalid } \\
\text { ade }\end{array} \\
\\
\\
\text { Não } \\
\text { definido } \\
\text { no } \\
\text { estudo }\end{array}$} & \multirow{2}{*}{\begin{tabular}{|c|}
$\begin{array}{c}\text { Diagnóstico } \\
\text { laboratorial }\end{array}$ \\
\\
Zaragatoas \\
orofaríngeas, \\
axilares e retais \\
e cultura
\end{tabular}} & \multirow{2}{*}{$\begin{array}{c}\text { Conduta } \\
\text { medicamentosa } \\
\text { majoritária }\end{array}$} \\
\hline 20 & $\begin{array}{c}\text { 2013/ Pressão de } \\
\text { colonização como fator } \\
\text { de risco para } \\
\text { colonização por } \\
\text { Acinetobacter spp } \\
\text { multirresistente e } \\
\text { Pseudomonas } \\
\text { aeruginosa resistente a } \\
\text { carbapenem em } \\
\text { unidade de terapia } \\
\text { intensiva }\end{array}$ & & & & & & & & & \\
\hline 21 & $\begin{array}{l}\text { 2013/ Perfil } \\
\text { epidemiológico das } \\
\text { infecções primárias de } \\
\text { corrente sanguínea em } \\
\text { uma unidade de terapia } \\
\text { intensiva neonatal }\end{array}$ & $\begin{array}{l}\text { Estudo } \\
\text { descritivo } \\
\text { retrospectivo }\end{array}$ & $\begin{array}{l}\text { Rio de Janeiro- } \\
\text { RJ }\end{array}$ & $\begin{array}{l}13 \text { pacientes/ } \\
\text { recém-nascido/ } \\
\text { feminino }\end{array}$ & $\begin{array}{l}\text { Staphylococcus } \\
\text { Coagulase } \\
\text { Negativo; S. } \\
\text { aureus }\end{array}$ & $\begin{array}{l}\text { Idade, peso ao nascer, } \\
\text { doença de base, o uso } \\
\text { de cateteres centrais e } \\
\text { fatores do hospedeiro }\end{array}$ & $\begin{array}{l}\text { Infecção de } \\
\text { corrente } \\
\text { sanguínea } \\
\text { relacionada a } \\
\text { cateter venoso } \\
\text { central (ICSRC) }\end{array}$ & $23 \%$ & $\begin{array}{c}\text { Critérios } \\
\text { clínicos }(46,25) \\
\text { e laboratoriais } \\
\text { com } \\
\text { hemoculturas } \\
(53,75)\end{array}$ & $\begin{array}{c}\text { Estudo com ênfase } \\
\text { em } \\
\text { microorganismos }\end{array}$ \\
\hline 22 & $\begin{array}{l}\text { 2012/ Nosocomial } \\
\text { infections in a pediatric } \\
\text { intensive care unit of a } \\
\text { developing country: } \\
\text { NHSN surveillance }\end{array}$ & $\begin{array}{l}\text { Estudo caso- } \\
\text { controle }\end{array}$ & Uberlândia-MG & $\begin{array}{l}\text { 172, } 38 \text { infectados/ } \\
\text { crianças/ } \\
\text { masculino }\end{array}$ & $\begin{array}{l}\text { Enterococcus } \\
\text { faecalis e } \\
\text { Escherichia coli }\end{array}$ & $\begin{array}{l}\text { Uso de dispositivos } \\
\text { invasivos como CVC ou } \\
\text { sonda nasogástrica, } \\
\text { tempo de permanência } \\
\text { na UTIP e uso de } \\
\text { antibióticos. }\end{array}$ & $\begin{array}{l}\text { Infecção do } \\
\text { trato urinário, } \\
\text { pneumonia, } \\
\text { bacteremia e } \\
\text { sepse }\end{array}$ & $8,10 \%$ & $\begin{array}{c}\text { Critérios } \\
\text { clínicos e } \\
\text { laboratoriais } \\
\text { com cultura de } \\
\text { urina, } \\
\text { contagem } \\
\text { bacteriana de } \\
\text { aspirado } \\
\text { traqueal e } \\
\text { hemocultura }\end{array}$ & $\begin{array}{l}\text { Incidência de três } \\
\text { IH (sepse, } \\
\text { pneumonia e } \\
\text { infecção do trato } \\
\text { urinário) }\end{array}$ \\
\hline 23 & $\begin{array}{l}\text { 2012/ Fatores de risco e } \\
\text { caracterização de } \\
\text { internações por } \\
\text { Plasmodium vivax em } \\
\text { unidades de terapia } \\
\text { intensiva pediátrica na } \\
\text { Amazônia brasileira }\end{array}$ & $\begin{array}{l}\text { Estudo } \\
\text { descritivo } \\
\text { retrospectivo }\end{array}$ & Manaus-AM & $\begin{array}{c}34 \text { pacientes/ 0-14 } \\
\text { anos/masculino }\end{array}$ & $\begin{array}{l}\text { Plasmodium } \\
\text { vivax e } P . \\
\text { falciparum }\end{array}$ & $\begin{array}{c}\text { Homens, idade }<5 \text { anos, } \\
\text { parasitemia periférica } \\
\text { superior a } 500 / \mathrm{mm}^{3} \mathrm{e} \\
\text { condição clínica aguda }\end{array}$ & $\begin{array}{l}\text { Infecção de } \\
\text { Corrente } \\
\text { Sanguínea }\end{array}$ & $14 \%$ & $\begin{array}{l}\text { Microscopia da } \\
\text { gota espessa } \\
\text { de sangue }\end{array}$ & $\begin{array}{c}\text { Cloroquina e } \\
\text { Primaquina para } \\
\text { infecção por P. } \\
\text { vivax e artemether } \\
\text { / lumefantrina por } 3 \\
\text { dias para infecção } \\
\text { por P. falciparum } \\
\text { não grave } \\
\end{array}$ \\
\hline
\end{tabular}

REAS / EJCH | Vol.12(11) | e4665 | DOI: https://doi.org/10.25248/reas.e4665.2020 Página 10 de 18 


\section{Revista Eletrônica Acervo Saúde / Electronic Journal Collection Health ISSN 2178-2091}

\begin{tabular}{|c|c|c|c|c|c|c|c|c|c|c|}
\hline \multicolumn{2}{|c|}{$\begin{array}{l}\text { Ano de publicação/ título } \\
\text { do artigo }\end{array}$} & \multirow{2}{*}{$\begin{array}{c}\text { Tipo de } \\
\text { estudo } \\
\\
\\
\\
\text { Estudo } \\
\text { descritivo, } \\
\text { retrospectivo } \\
\text { (dados } \\
\text { secundários) }\end{array}$} & \multirow{2}{*}{$\begin{array}{c}\begin{array}{c}\text { Local do } \\
\text { estudo }\end{array} \\
\\
\text { Campinas-SP }\end{array}$} & \multirow{2}{*}{$\begin{array}{c}\text { Tamanho da } \\
\text { amostra/faixa } \\
\text { etária/sexo mais } \\
\text { prevalente } \\
\\
\\
150 \text { pacientes/ } \\
\text { Média de } 52 \text { anos } \\
\text { (colonizados) e } 58 \\
\text { anos (infectados)/ } \\
\text { masculino }\end{array}$} & \multirow{2}{*}{$\begin{array}{c}\begin{array}{c}\text { Patógenos } \\
\text { mais } \\
\text { frequentes }\end{array} \\
\\
\text { Enterococos } \\
\text { resistentes à } \\
\text { vancomicina }\end{array}$} & \multirow{2}{*}{$\begin{array}{l}\text { Fatores de risco } \\
\text { observados } \\
\\
\text { A contaminação do } \\
\text { ambiente foi o principal } \\
\text { fator de risco para } \\
\text { infecção }\end{array}$} & \multirow{2}{*}{$\begin{array}{c}\begin{array}{c}\text { Sítio } \\
\text { anatômico }\end{array} \\
\\
\\
\\
\text { Infecção de } \\
\text { corrente } \\
\text { sanguínea } \\
\text { relacionada a } \\
\text { cateter venoso } \\
\text { central (ICSRC) }\end{array}$} & \multirow{2}{*}{\begin{tabular}{|c|}
$\begin{array}{c}\text { Taxa de } \\
\text { mortalid } \\
\text { ade }\end{array}$ \\
\\
\\
\\
\\
\\
\\
\\
\end{tabular}} & \multirow{2}{*}{$\begin{array}{l}\text { Diagnóstico } \\
\text { laboratorial }\end{array}$} & \multirow{2}{*}{\begin{tabular}{|c}
$\begin{array}{c}\text { Conduta } \\
\text { medicamentosa } \\
\text { majoritária }\end{array}$ \\
\\
Vancomicina, \\
metronidazol, \\
ciprofloxacina ou \\
cefalosporina de \\
terceira geração \\
foram utilizados \\
previamente por 47 \\
(31,3\%), 31 \\
(20,7\%), 24 (16\%) \\
e $24(16 \%)$ \\
pacientes, \\
respectivamente.
\end{tabular}} \\
\hline 24 & $\begin{array}{l}\text { 2012/ Prevenção bem- } \\
\text { sucedida da } \\
\text { transmissão de } \\
\text { enterococos resistentes } \\
\text { à vancomicina em um } \\
\text { hospital público } \\
\text { universitário brasileiro }\end{array}$ & & & & & & & & & \\
\hline 25 & $\begin{array}{c}\text { 2012/ Infecção } \\
\text { hospitalar em uma } \\
\text { unidade de terapia } \\
\text { intensiva neonatal do } \\
\text { Sul do Brasil }\end{array}$ & $\begin{array}{l}\text { Estudo coorte } \\
\text { prospectivo }\end{array}$ & Tubarão-SC & $\begin{array}{l}239 \text { pacientes/ } \\
\text { recém-nascido/ } \\
\text { não definido no } \\
\text { estudo }\end{array}$ & $\begin{array}{l}\text { S. coagulase } \\
\text { negativa; } \\
\text { enterobacter } \\
\text { sp. }\end{array}$ & Não definido no estudo & $\begin{array}{l}\text { Infecção de } \\
\text { Corrente } \\
\text { Sanguínea }\end{array}$ & $33,80 \%$ & Hemocultura & $\begin{array}{l}\text { Não definido no } \\
\text { estudo }\end{array}$ \\
\hline 26 & $\begin{array}{c}\text { 2011/ Prevenção de } \\
\text { infecções associadas a } \\
\text { cateter em Unidade de } \\
\text { Terapia Intensiva } \\
\text { Pediátrica: impacto de } \\
\text { um programa } \\
\text { educacional levantando } \\
\text { políticas de inserção e } \\
\text { cuidados com cateteres } \\
\text { venosos centrais em um } \\
\text { hospital universitário } \\
\text { brasileiro }\end{array}$ & $\begin{array}{l}\text { Estudo de } \\
\text { coorte } \\
\text { prospectivo }\end{array}$ & São Paulo-SP & $\begin{array}{l}246 \text { pacientes/ } \\
\text { adultos/ masculino }\end{array}$ & Gram positivas & $\begin{array}{l}\text { Prematuridade, sepse } \\
\text { precoce }\end{array}$ & $\begin{array}{l}\text { Infecção de } \\
\text { Corrente } \\
\text { Sanguinea }\end{array}$ & $12,10 \%$ & $\begin{array}{c}\text { Critérios } \\
\text { clínicos e } \\
\text { laboratoriais } \\
\text { com } \\
\text { hemoculturas }\end{array}$ & $\begin{array}{c}\text { Estudo } \\
\text { epidemiológico } \\
\text { com ênfase em } \\
\text { incidência de IH. }\end{array}$ \\
\hline
\end{tabular}

REAS / EJCH | Vol.12(11) | e4665 | DOI: https://doi.org/10.25248/reas.e4665.2020 Página 11 de 18 
Revista Eletrônica Acervo Saúde / Electronic Journal Collection Health ISSN 2178-2091

\begin{tabular}{|c|c|c|c|c|c|c|c|c|c|c|}
\hline \multicolumn{2}{|c|}{$\begin{array}{l}\text { Ano de publicação/ título } \\
\text { do artigo }\end{array}$} & \multirow{2}{*}{$\begin{array}{c}\text { Tipo de } \\
\text { estudo } \\
\\
\\
\\
\text { Estudo } \\
\text { epidemiológico } \\
\text { com } \\
\text { delineamento } \\
\text { transversal }\end{array}$} & \multirow{2}{*}{$\begin{array}{l}\begin{array}{c}\text { Local do } \\
\text { estudo }\end{array} \\
\\
\text { Sul de Santa } \\
\text { Catarina-SC }\end{array}$} & \multirow{2}{*}{$\begin{array}{c}\text { Tamanho da } \\
\text { amostra/faixa } \\
\text { etária/sexo mais } \\
\text { prevalente } \\
\\
\\
\\
\\
83 \text { pacientes/ } \\
\text { Idade média de } \\
48,6 \text { anos/ } \\
\text { masculino }\end{array}$} & \multirow{2}{*}{$\begin{array}{c}\begin{array}{c}\text { Patógenos } \\
\text { mais } \\
\text { frequentes }\end{array} \\
\\
\begin{array}{c}\text { Staphylococcus } \\
\text { coagulase } \\
\text { negativa }\end{array}\end{array}$} & \multirow{2}{*}{$\begin{array}{c}\text { Fatores de risco } \\
\text { observados } \\
\\
\\
\text { Tempo de permanência } \\
\text { na UTI, comorbidades } \\
\text { associadas. }\end{array}$} & \multirow{2}{*}{\begin{tabular}{|c}
$\begin{array}{c}\text { Sítio } \\
\text { anatômico }\end{array}$ \\
\\
\\
\\
Infecção de \\
corrente \\
sanguínea \\
relacionada a \\
cateter venoso \\
central (ICSRC)
\end{tabular}} & \multirow{2}{*}{\begin{tabular}{|c|}
$\begin{array}{c}\text { Taxa de } \\
\text { mortalid } \\
\text { ade }\end{array}$ \\
\\
\\
\\
\\
\\
$53 \%$ \\
\end{tabular}} & \multirow[b]{2}{*}{$\begin{array}{c}\text { Diagnóstico } \\
\text { laboratorial } \\
\\
\text { Critérios } \\
\text { clínicos e } \\
\text { laboratoriais } \\
(49 \%) \text { com } \\
\text { hemoculturas } \\
\text { (método } \\
\text { semiautomatiza } \\
\text { do) três meios } \\
\text { de cultura: ágar } \\
\text { chocolate, } \\
\text { MacConkey e } \\
\text { Sabouraud. }\end{array}$} & \multirow[b]{2}{*}{$\begin{array}{c}\begin{array}{c}\text { Conduta } \\
\text { medicamentosa } \\
\text { majoritária }\end{array} \\
\text { Dos } 83,16(19,3 \%) \\
\text { utilizaram somente } \\
\text { um antibacteriano, } \\
24(28,9 \%) \\
\text { utilizaram dois, } 17 \\
(20,5 \%) \text { utilizaram } \\
\text { três, } 9(10,8 \%) \\
\text { receberam quatro, } \\
17(20,5 \%) \\
\text { utilizaram cinco ou } \\
\text { mais } \\
\text { antibacterianos } \\
\text { diferentes durante } \\
\text { o tempo de } \\
\text { permanência na } \\
\text { UTI }\end{array}$} \\
\hline 27 & $\begin{array}{l}\text { 2011/ Sepse associada } \\
\text { ao cateter venoso } \\
\text { central em pacientes } \\
\text { adultos internados em } \\
\text { unidade de terapia } \\
\text { intensiva }\end{array}$ & & & & & & & & & \\
\hline 28 & $\begin{array}{l}\text { 2011/ Fatores de risco } \\
\text { para infecção de } \\
\text { corrente sanguínea } \\
\text { relacionada a cateter: } \\
\text { um estudo multicêntrico } \\
\text { prospectivo em } \\
\text { unidades de terapia } \\
\text { intensiva brasileiras }\end{array}$ & $\begin{array}{l}\text { Estudo de } \\
\text { coorte } \\
\text { multicêntrico }\end{array}$ & São Paulo-SP & $\begin{array}{l}555 \text { pacientes/ } \\
\text { Idade média de } \\
53,9 \text { anos/ } \\
\text { masculino }\end{array}$ & $\begin{array}{c}\text { Acinetobacter } \\
\text { baumannii; } P . \\
\text { aeruginosa; } K \\
\text { pneumoniae }\end{array}$ & $\begin{array}{c}\text { Tempo de permanência } \\
\text { na UTI }\end{array}$ & $\begin{array}{l}\text { Infecção de } \\
\text { corrente } \\
\text { sanguínea } \\
\text { relacionada a } \\
\text { cateter venoso } \\
\text { central (ICSRC) }\end{array}$ & $\begin{array}{c}\text { Não } \\
\text { definido } \\
\text { no } \\
\text { estudo }\end{array}$ & Hemocultura & $\begin{array}{l}\text { Estudo com ênfase } \\
\text { em fatores de risco }\end{array}$ \\
\hline 29 & $\begin{array}{c}\text { 2011/ Surto de infecção } \\
\text { neonatal por um clone } \\
\text { endêmico de Serratia } \\
\text { marcescens }\end{array}$ & $\begin{array}{l}\text { Série de casos } \\
\text { (com grupo } \\
\text { controle) }\end{array}$ & Belém-PA & $\begin{array}{l}26 \text { Pacientes/ } \\
\text { recém-nascido/ } \\
\text { masculino }\end{array}$ & $\begin{array}{c}\text { Serratia } \\
\text { marcescens }\end{array}$ & $\begin{array}{c}\text { Baixo peso ao } \\
\text { nascimento, } \\
\text { hospitalização } \\
\text { prolongada, parto } \\
\text { prematuro e exposição à } \\
\text { pressão positiva } \\
\text { contínua nas vias } \\
\text { aéreas }\end{array}$ & $\begin{array}{l}\text { Infecção de } \\
\text { Corrente } \\
\text { Sanguínea }\end{array}$ & $\begin{array}{c}\text { Não } \\
\text { definido } \\
\text { no } \\
\text { estudo }\end{array}$ & $\begin{array}{l}\text { Hemocultura e } \\
\text { zaragatoas } \\
\text { retais }\end{array}$ & $\begin{array}{l}\text { Tazobactam com } \\
\text { piperacilina. }\end{array}$ \\
\hline
\end{tabular}

REAS / EJCH | Vol.12(11) | e4665 | DOI: https://doi.org/10.25248/reas.e4665.2020 Página 12 de 18 
Revista Eletrônica Acervo Saúde / Electronic Journal Collection Health ISSN 2178-2091

\begin{tabular}{|c|c|c|c|c|c|c|c|c|c|c|}
\hline \multicolumn{2}{|c|}{$\begin{array}{l}\text { Ano de publicação/ título } \\
\text { do artigo }\end{array}$} & \multirow{2}{*}{$\begin{array}{c}\text { Tipo de } \\
\text { estudo } \\
\\
\text { Estudo } \\
\text { observacional } \\
\text { do tipo caso e } \\
\text { controle (pré e } \\
\text { pós- } \\
\text { intervenção) }\end{array}$} & \multirow{2}{*}{$\begin{array}{c}\begin{array}{c}\text { Local do } \\
\text { estudo }\end{array} \\
\\
\text { Uberlândia-MG }\end{array}$} & \multirow{2}{*}{$\begin{array}{c}\text { Tamanho da } \\
\text { amostra/faixa } \\
\text { etária/sexo mais } \\
\text { prevalente } \\
\\
\\
\\
251 \text { pacientes/ } \\
\text { recém-nascido/ } \\
\text { masculino }\end{array}$} & \multirow{2}{*}{$\begin{array}{c}\begin{array}{c}\text { Patógenos } \\
\text { mais } \\
\text { frequentes }\end{array} \\
\\
\text { Staphylococcus } \\
\text { coagulase- } \\
\text { negativo }\end{array}$} & \multirow{2}{*}{$\begin{array}{c}\begin{array}{c}\text { Fatores de risco } \\
\text { observados }\end{array} \\
\\
\text { O uso de nutrição } \\
\text { parenteral e ventilação } \\
\text { mecânica, exposição a > } \\
3 \text { antibióticos e tempo } \\
\text { de internação > } 8 \text { dias. }\end{array}$} & \multirow{2}{*}{\begin{tabular}{|c|}
$\begin{array}{c}\text { Sítio } \\
\text { anatômico }\end{array}$ \\
\\
Infecção de \\
corrente \\
sanguínea \\
relacionada a \\
cateter venoso \\
central (ICSRC)
\end{tabular}} & \multirow{2}{*}{$\begin{array}{c}\begin{array}{c}\text { Taxa de } \\
\text { mortalid } \\
\text { ade }\end{array} \\
\\
\\
\text { Não } \\
\text { definido } \\
\text { no } \\
\text { estudo }\end{array}$} & \multirow{2}{*}{$\begin{array}{l}\text { Diagnóstico } \\
\text { laboratorial }\end{array}$} & \multirow{2}{*}{$\begin{array}{c}\begin{array}{c}\text { Conduta } \\
\text { medicamentosa } \\
\text { majoritária }\end{array} \\
\begin{array}{c}\text { Análise pré e pós- } \\
\text { intervenção) }\end{array}\end{array}$} \\
\hline 30 & $\begin{array}{c}2011 / \text { Redução de } \\
\text { infecções de corrente } \\
\text { sanguínea associadas a } \\
\text { cateter por meio de } \\
\text { procedimentos em } \\
\text { recém-nascidos } \\
\text { internados em unidade } \\
\text { de terapia intensiva de } \\
\text { hospital universitário no } \\
\text { Brasil }\end{array}$ & & & & & & & & & \\
\hline 31 & $\begin{array}{l}2010 / \text { Infecções } \\
\text { nosocomiais em uma } \\
\text { unidade de terapia } \\
\text { intensiva neonatal } \\
\text { brasileira: um estudo de } \\
\text { vigilância de } 4 \text { anos }\end{array}$ & $\begin{array}{c}\text { Estudo } \\
\text { descritivo } \\
\text { prospectivo, } \\
\text { epidemiológico }\end{array}$ & Uberlândia-MG & $\begin{array}{l}1443 \text { pacientes/ } \\
\text { recém-nascido/ } \\
\text { não definido no } \\
\text { estudo }\end{array}$ & $\begin{array}{l}\text { Staphylococcus } \\
\text { coagulase- } \\
\text { negativa; } S . \\
\text { aureus }\end{array}$ & $\begin{array}{l}\text { Ventilação mecânica, } \\
\text { nutrição parenteral total, } \\
\text { sonda orogástrica, } \\
\text { antibioticoterapia prévia, } \\
\text { uso de CVC e peso ao } \\
\text { nascer de } 751-1.000 \mathrm{~g}\end{array}$ & $\begin{array}{l}\text { Infecção } \\
\text { Primária de } \\
\text { Corrente } \\
\text { Sanguínea- } \\
\text { IPCS }\end{array}$ & $11,90 \%$ & $\begin{array}{c}\text { Critérios } \\
\text { clínicos e } \\
\text { laboratoriais } \\
\text { com cultura das } \\
\text { amostras de } \\
\text { sangue (203 } \\
\text { amostras), } \\
\text { secreção ocular } \\
\text { (52 amostras) e } \\
\text { urina (12 } \\
\text { amostras) }\end{array}$ & $\begin{array}{l}\text { Estudo com ênfase } \\
\text { em padrões de } \\
\text { susceptibiidade } \\
\text { antimicrobiana }\end{array}$ \\
\hline 32 & $\begin{array}{c}2010 / \text { Infecção } \\
\text { hospitalar em unidade } \\
\text { de terapia intensiva de } \\
\text { hospital universitário } \\
\text { brasileiro }\end{array}$ & $\begin{array}{c}\text { Estudo } \\
\text { descritivo } \\
\text { prospectivo, } \\
\text { epidemiológico }\end{array}$ & Belo Horizonte & $\begin{array}{l}1889 \text { pacientes/ } \\
\text { Idade média de } \\
53,3 \text { anos/ } \\
\text { masculino }\end{array}$ & $\begin{array}{l}\text { Candida } \\
\text { albicans }\end{array}$ & $\begin{array}{c}\text { O tempo de internação } \\
\text { superior a quatro dias, } \\
\text { episódios de infecções } \\
\text { comunitárias, } \\
\text { colonização por } \\
\text { microrganismos } \\
\text { resistentes e o uso de } \\
\text { procedimentos invasivos } \\
\text { associados ao } \\
\text { desenvolvimento de } \\
\text { infecções hospitalares, } \\
\text { com altos índices de } \\
\text { Risco Relativo (mais de } \\
2,4 \text { ) }\end{array}$ & $\begin{array}{l}\text { Infecção do } \\
\text { trato urinário, } \\
\text { associadas à } \\
\text { sondagem } \\
\text { vesical de } \\
\text { demora } \\
(37,6 \%)\end{array}$ & $\begin{array}{c}77 \\
(39,5 \%)\end{array}$ & $\begin{array}{c}\text { Critérios } \\
\text { laboratoriais } \\
\text { (cultura) }\end{array}$ & $\begin{array}{c}\text { Estudo com ênfase } \\
\text { na incidência de } \\
\text { infecção hospitalar } \\
\text { em UTI }\end{array}$ \\
\hline
\end{tabular}

Fonte: Gomes AAG e Silva MR, 2020.

REAS / EJCH | Vol.12(11) | e4665 | DOI: https://doi.org/10.25248/reas.e4665.2020 Página 13 de 18 
Dos 32 artigos selecionados, $84.4 \%$ foram publicados em periódicos nacionais, $18.7 \%$ em periódicos internacionais e 3.1\% são teses de doutorado da Universidade Federal de Minas Gerais (UFMG). Além disso, $21.8 \%$ dos artigos foram publicados no ano de $2013,15.6 \%$ em $2011,12.5 \%$ em $2018,12.5 \%$ em $2012,9.4 \%$ em 2015, 6.2\% em 2019, 6.2\% em 2015, 6.2\% em 2014, 6.2\% em 2010 e 3.7\% em 2017 (Figura 3).

Figura 3 - Número de artigos selecionados por ano após a utilização dos critérios de exclusão.

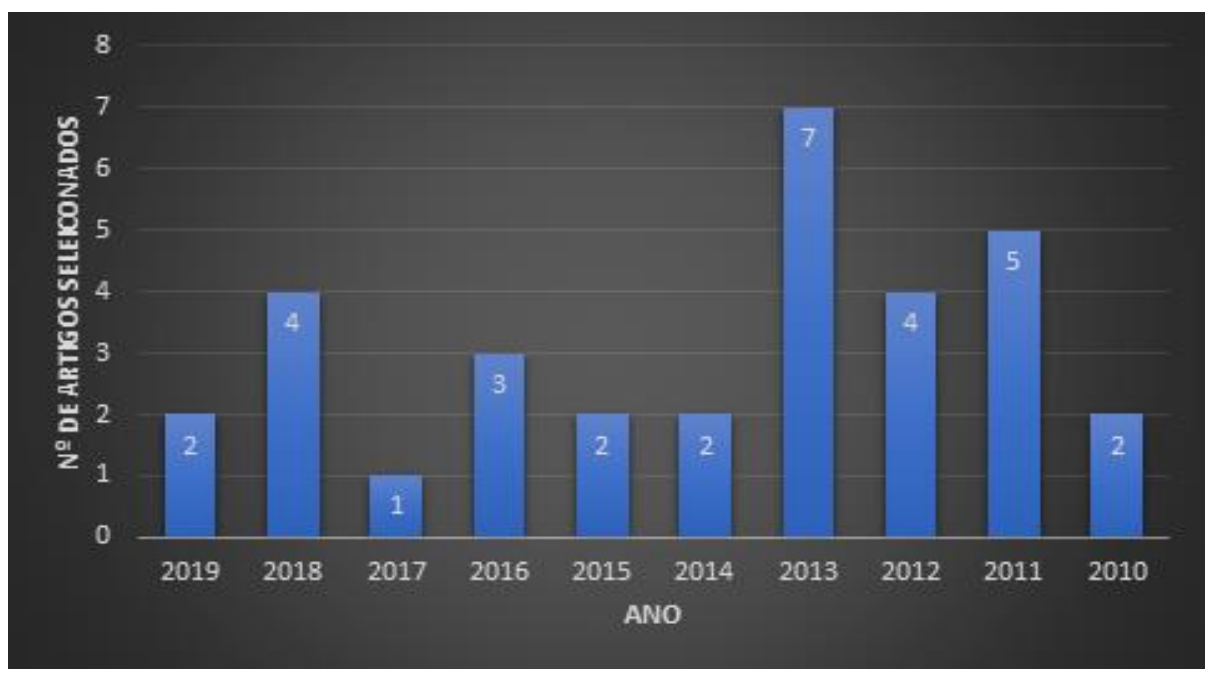

Fonte: Gomes AAG e Silva MR, 2020.

Quanto ao delineamento da pesquisa, $31.2 \%$ são do tipo coorte, $25 \%$ são descritivos, $18.7 \%$ são observacionais transversais, $15.6 \%$ foram de caso-controle, $3.2 \%$ são série de casos, $3.2 \%$ do tipo relato de caso, e $3.2 \%$ não foram postos no artigo (Figura 4 ).

Figura 4 - Tipos de delineamento das pesquisas selecionadas após critérios de exclusão.

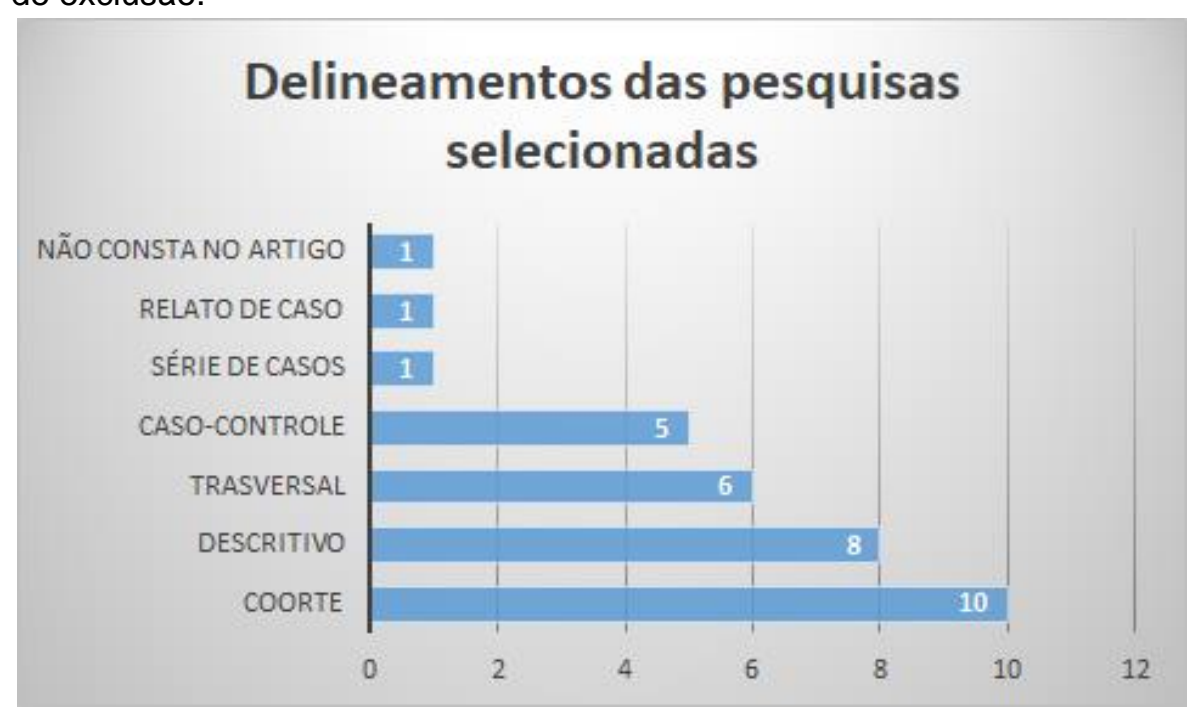

Fonte: Gomes AAG e Silva MR, 2020.

Foram selecionados estudos realizados em UTIs brasileiras, sendo que $50 \%$ foram feitos na região Sudeste, $9.4 \%$ na região sul, $9.4 \%$ no Norte, $6.2 \%$ no Nordeste, $3.1 \%$ no Centro-oeste e $15.6 \%$ dos artigos não relataram o local do estudo. Levando em conta a amostra de pacientes, foram avaliados em média 298,8 pacientes por pesquisa. Dentre as 32 pesquisas selecionadas, $68.7 \%$ tinham prevalência de sexo masculino, $15.6 \%$ apresentaram prevalência do sexo feminino e, $15.6 \%$ não relataram. Além disso, a faixa etária dos pacientes variou de recém-nascido a 94 anos. 
Dentre os locais anatômicos mais acometidos, a infecção de corrente sanguínea esteve presente em $25 \%$ dos estudos, no qual a hemocultura foi utilizada como diagnóstico em $87.5 \%$ dessas infecções. Em $21 \%$ dos 32 estudos foram encontradas infecções do trato respiratório, diagnosticadas por meio de análise de aspirado de secreção.

Ademais, foram vistas infecções do trato urinário e infecções da corrente sanguínea associada a uso de cateter central em $15 \%$ dos estudos, sepse em $7 \%$, infecções intra-abdominais em $4 \%$ e infecções do sítio cirúrgico em $2 \%$ dos artigos avaliados. Por fim, $8 \%$ dos estudos não apresentaram o local anatômico mais acometido.

Outro ponto importante analisado foi que em oito estudos foi descrita a presença de diferentes microrganismos (vírus, bactérias e parasitas). As bactérias foram descritas na maioria dos estudos estando presentes: Estafilococos coagulase-negativa, Pseudomonas aeruginosa, Staphylococcus aureus, Klebsiella pneumoniae, Acinetobacter baumanni, Acinetobacter sp., klebsiella sp., S. aureus resistente a meticilina, $S$. epidermidis, enterobacter sp., S. marcescens, gram negativa e gram positiva não especificadas, Enterococcus faecalis, Ralstonia mannitolilytica, Porphyromonas gingivalis, Treponema denticola, Escherichia coli, Serratia marcescens, Estafilococos haemolyticus, Pseudomonas sp., Enterococcus sp., S. aureus resistente a meticilina, $P$. aeruginosa resistente a carbapenem e Enterecoccus resistente à vancomicina. Além disso, os fungos Candida parapsilosis e o Candida albicans foram descritos em $3.1 \%$ dos artigos, da mesma forma que os parasitas Plasmodium vivax e Plasmodium falciparum. É importante destacar a presença de Rinovírus, Vírus sincicial respiratório e HCoV em $3.1 \%$ dos manuscritos.

Os principais fatores de risco associados à infecção em UTI analisados foram: pacientes com doenças de base, principalmente Diabetes Mellitus e hipertensão, tempo de permanência na UTI, paciente pós-cirúrgico, uso de mecanismos invasivos-principalmente ventilação mecânica-, histórico de câncer e infarto agudo do miocárdio, baixo peso ao nascer, prematuridade, sexo masculino, uso prévio de antibióticos e contaminação do ambiente.

A taxa de mortalidade variou de $3.40 \%$, presente na região Sudeste até $70 \%$, referente a uma UTI da região Norte. Dentre todos os hospitais analisados, houve média de $30.31 \%$ de mortalidade. É importante citar que 11 hospitais não apresentaram essa avaliação.

Em relação às condutas, foi visto que a antibioticoterapia empírica foi utilizada para diminuir as taxas de comorbidades e complicações nos pacientes. Dentre os medicamentos utilizados, os mais presentes foram as cefalosporinas de $3^{\underline{a}}$ e $4^{\underline{a}}$ geração, associada à carbapenêmicos e às quinolonas.

Nos casos de infecção fúngica, foi utilizado liposomal amphotericin B (L-AMB). Nos casos de infecção por $P$. vivax foi utilizado cloroquina e primaquina, e nas infecções por $P$. falciparum, lumefantrina por três dias. Em um hospital do estado de São Paulo, foram utilizados treinamento e capacitação da equipe de saúde do hospital, o que proporcionou diminuição da taxa de infecção observada.

\section{DISCUSSÃO}

Em relação aos delineamentos das 32 pesquisas avaliadas, 31.2\% são do tipo coorte, nível de evidência 2B (Oxford Centre for Evidence-Based Medicine-níveis de evidência científica, 2014), sejam coorte histórica ou seguimento de pacientes não tratados de grupo de controle de ensaio clínico randomizado o que demonstra a qualidade dos estudos que foram utilizados na revisão.

Conforme as regiões brasileiras descritas nos manuscritos encontrados, 16 UTI relatadas nas pesquisas encontram-se no sudeste do Brasil, seguida pela região Sul, Norte, Nordeste e, por fim, Centro-oeste. Essa concentração espacial da quantidade de artigos publicados está diretamente relacionada à localização das universidades públicas, primordialmente as estaduais e federais, uma vez que essas são responsáveis pela maioria da atividade científica, padrão típico de países em desenvolvimento. Mas esse fato ocorre não somente pela quantidade de Instituições de Ensino Superior (IES), mas também por conta da vocação dessas regiões em investigar o tema (SANTOS A, et al., 2012; SIDONE OJG, et al., 2016). 
No sentindo contrário à quantidade de artigos publicados, a taxa de mortalidade é consideravelmente maior nas UTI presentes na região Norte do que na região Sul. Essa realidade pode se desenvolver por meio da má distribuição demográfica dos médicos pelo Brasil, no qual um morador da capital de qualquer estado do Sul e Sudeste contava em 2011 com quatro vezes mais médicos que um habitante do interior de qualquer outra região (Conselho Federal de Medicina, 2020).

Somado a isso, no Norte, apenas $56 \%$ dos médicos possuem residência médica, enquanto que no Sudeste esse percentual chega a 78,1\%. Ademais, a cultura punitiva é responsável pela subnotificação e omissão dos eventos por parte dos profissionais da saúde, constituindo uma barreira para realização de investigações que poderiam gerar medidas preventivas eficazes e a verdadeira taxa de mortalidade em UTI nas regiões brasileiras (MACHADO MH, et al., 1993; FIGUEIREDO ML e D'INNOCENZO M, 2017)."

Em relação ao sexo, o masculino se destacou frente ao feminino. Os homens, mais do que as mulheres, têm estilo de vida pouco saudável, o que predispõe a doenças crônicas. Somado a vida pouco saudável, o Staphylococcus aureus possui como principal reservatório o homem, onde este microrganismo é o agente mais comum de infecções piogênicas localizadas na pele ou em regiões mais profundas como furúnculos, foliculites, osteomielites, endocardites, pneumonias, septicemias fatais e outros tipos de manifestações. Podese encontrar este microrganismo colonizado em várias partes do corpo como fossas nasais, garganta, intestinos e pele, sendo que cavidade nasal tem sido apontada como a área mais frequentemente positiva $\mathrm{e}$ a mais importante fonte do mesmo (BIDINOTTO DNPB, et al., 2016; SAMPAIO CPS, et al., 2013).

É importante ressaltar que a Klebsiella sp. e o Citrobacter normalmente compõem a microbiota do intestino do homem, principalmente nas fezes. Assim, devido à proximidade com o aparelho gênito-urinário, é frequente a ocorrência dela e de outras enterobactérias na infecção de trato urinário (ARAÚJO PL, et al., 2018).

$\mathrm{Na}$ revisão de literatura também foram identificados os métodos de diagnóstico e aquele que esteve presente em $39 \%$ dos artigos foi a hemocultura. Vale destacar que as metodologias atuais para hemocultura automatizada são mais sensíveis e permitem a detecção rápida de baixos níveis de bacteremia mesmo em pacientes em uso prévio de antimicrobianos. Seu uso relaciona-se com a incidência de infecções de corrente sanguínea observadas nos artigos sobre os demais sítios anatômicos de infecção, visto que ainda é um dos métodos bastante difundidos para esse diagnóstico (RIEDEL S e CARROLL K, 2010).

Ainda que muitos profissionais tenham capacidade técnica de realizar a hemocultura, é preciso reconhecer as dificuldades de natureza estrutural apontadas nos artigos para se realizar um fidedigno diagnóstico microbiológico. Há ainda a ocorrência de contaminação do material coletado com certa frequência. (DOERN GV, et al, 2019; PARK WB, et al., 2015). Vale ressaltar que alguns artigos, apesar de atenderem os critérios de inclusão, não apresentaram os métodos diagnósticos, corroborando assim para a falta de tratamento especifico frente aos tipos de microrganismos.

Além disso, é importante relatar que as infecções mais comuns e clinicamente importantes adquiridas na UTI são aquelas associadas aos dispositivos de suporte que os pacientes na UTI necessitam frequentemente. Sabe-se que estes recursos diagnósticos, terapêuticos e de monitorização são, em geral, invasivos ao paciente - como cateteres, tubos e sondas. Face a isto encontra-se frequentemente, nos estudos, infecção da corrente sanguínea relacionada ao cateter intravascular, pneumonia associada ao ventilador e infecção do trato urinário associado à sondagem vesical (LO E, et al., 2008; CHENOWETH S, 2011).

A infecção do trato urinário (ITU) é a infecção relacionadas a assistência em saúde mais comum, responsável por mais de $40 \%$ de todas as infecções hospitalares (LO E et al., 2008). Enquanto a maioria das ITU associadas ao cateter não causa morbimortalidade grave ou aumenta significativamente os custos hospitalares, o impacto cumulativo dessas infecções frequentes é grande (LO E et al., 2008; CHENOWETH S, 2011).

É importante citar a pneumonia associada ao ventilador, que é uma infecção do tecido pulmonar que se desenvolve 48 horas ou mais após a intubação em pacientes sobre ventilação mecânica. Pacientes nessas condições podem ter seus quadros agravados em decorrência da existências de doenças de base, uso de agentes sedativos, aspiração presenciada, decúbito horizontal, troca de circuitos respiratórios, reentubação e realização de broncoscopia Esse tipo de pneumonia é a segunda infecção hospitalar mais comum e ocorre frequentemente no cenário de intubação endotraqueal e ventilação mecânica (COFFIN SE et al., 2008). 
Ademais, os cateteres venosos arteriais e centrais são frequentemente usados em pacientes de terapia intensiva devido à necessidade de monitoramento hemodinâmico e terapêutica intravenosa. As infecções da corrente sanguínea envolvendo esses cateteres são comuns em UTIs e estão associadas à significativa morbimortalidade (ROCHA IV et al., 2015; BORDIGNON JC e LIMA LR, 2017).

Em relação a etiologia das infecções por ponta de cateteres venosos arteriais e centrais, os Staphylococcus spp são os mais frequentemente encontrados por serem mais resistentes no meio ambiente, com capacidade de sobreviver por meses em amostras clínicas secas, além de serem relativamente resistentes ao calor e tolerantes a altas concentrações salinas. Outros micro-organismos como os bacilos Gram-negativos, a Candida sp e o Enterococcus sp também possuem importante participação nos episódios infecciosos.

Evidências na literatura mostram que, no isolamento de bactérias provenientes de diferentes sítios de inserção do corpo humano, o Staphylococcus coagulase negativa (SCN) é a espécie mais comumente encontrada e o Staphylococcus aureus, a mais virulenta. Estes micro-organismos são considerados importantes agentes de infecções nosocomiais nos hospitais do Brasil além de estarem associados a um grande índice de morbimortalidade, como observado nos artigos analisados. (ROCHA IV et al., 2015; BORDIGNON JC e LIMA LR, 2017). Com isso, os altos índices de infecções da Corrente Sanguínea podem justificar o maior número de estudos para infecção de corrente sanguínea observados na presente revisão, em contrapartida dos demais sítios de infecção.

De acordo com os artigos avaliados, foi visto que certas características aumentam o risco de infecções nas UTI, contribuindo para o aumento da pressão seletiva (levando ao surgimento de organismos multirresistentes) e/ou aumento da pressão de colonização (levando à contenção ineficaz destes organismos). Estão a presença de idade avançada, alta gravidade da doença, hospitalização prolongada, uso de dispositivos invasivos (particularmente um cateter vascular central - CVC), ventilação mecânica, cateterismo uretral, uso de antibióticos e práticas de incapacidade para prevenção e controle de infecções nosocomiais (ANVISA, 2017; COFFIN SE, et al., 2008).

Além disso, estratégias para impedir o surgimento de organismos multirresistentes que não envolvem alterações na utilização de antimicrobianos (que afetam a pressão seletiva) passaram a ser essenciais e elas envolvem principalmente medidas de controle de infecção (que afetam a pressão de colonização e a transmissão de paciente para paciente). Atenção cuidadosa a essas atividades tem sido usada para conter surtos de organismos resistentes (DALBEN M F et al., 2013; RESENDE et al., 2011).

A adesão à higiene das mãos, treinamento, capacitação da equipe de saúde e implementação de estratégias específicas do manuseio dos dispositivos para diminuir a infecção devem ser realizadas periodicamente em todas UTI.

Um engajamento entre as agências de saúde pública federal (Agencia Nacional de Vigilância Sanitária Anvisa), estadual e local e os profissionais de saúde das instituições (Comissões de Controle de Infecção Hospitalar - $\mathrm{CCIH}$ ) torna-se vital para a implantação, sustentabilidade e expansão de um programa de vigilância e prevenção de infecções relacionadas a assistência em saúde.(ANVISA, 2017; RESENDE DS et al., 2011).

\section{CONSIDERAÇÕES FINAIS}

As infecções nosocomiais são frequentes em unidades de terapia intensiva (UTIs). Os patógenos mais observados nessas localidades fazem parte da microbiota endógena, mas tem se mostrado cada vez mais resistentes devido à utilização de agentes microbianos de maneira desordenada e a falta de capacitação dos profissionais de saúde. Os patógenos mais comuns isolados em UTIs incluem Staphylococcus aureus resistente ou não a meticilina, Staphylococcus coagulase-negativo, entre outros. Reitera-se a importância da higienização das mãos adequada e precauções de contato com pacientes infectados e educação continuada dos profissionais, com o objetivo de prevenir a infecção e a disseminação de microrganismos em UTI. 


\section{REFERÊNCIAS}

1. ARAÚJO PL, et al. Prevalência de infecção relacionada à assistência à saúde em pacientes internados em unidade de terapia intensiva. Revista electrónica trimestral de enfermería, 2018; 52.

2. BIDINOTTO DNPB, et al. A saúde do homem: doenças crônicas não transmissíveis e vulnerabilidade social. Revista Latino Americana de Enfermagem. São Paulo, 2016.

3. BORDIGNON JC, LIMA LR. Etiologia de infecções hospitalares e perfil de sensibilidade aos antimicrobianos em um hospital do Sudoeste do Paraná, Brasil. Revista Brasileira de Análises Clínicas, 2017;49:3.

4. BRASIL, MINISTÉRIO DA SAÚDE (MS) e AGÊNCIA NACIONAL DE VIGILÂNCIA SANITÁRIA (ANVISA). Programa Nacional de Prevenção e Controle de Infecções Relacionadas à Assistência à Saúde (2016-2020). Brasília: Ministério Da Saúde, 2017.

5. CHENOWETH CE, SAINT S. Urinary Tract InfectionsInfectious Disease Clinics of North Americalnfect Dis Clin North Am, 2011.

6. COELHO MS, et al. Higienização das mãos como estratégia fundamental no controle de infecção hospitalar: um estudo quantitativo. Revista electrónica trimestral de Enfermería, 2011;21.

7. COFFIN SE, et al. Strategies to Prevent Ventilator-Associated Pneumonia in Acute Care Hospitals. Infection Control \& Hospital Epidemiology, 2018; 29:31-40.

8. CONSELHO FEDERAL DE MEDICINA. Conselho Regional de Medicina do Estado de São Paulo. Estudo de projeção "Concentração de Médicos no Brasil em 2020". 2019. Disponível em: https://portal.cfm.org.br/images/stories/pdf/estudo_demografia_junho.pdf. Acesso em: 21 mar. 2020.

9. COSTA M, et al. Principais micro-organismos responsáveis por infecções relacionadas à assistência em saúde (iras) em UTIs: uma revisão integrativa. Revista eletrônica da Faculdade Evangélica de Ceres, 2020; vol. 8:1.

10. DALBEN M F, et al. Colonization pressure as a risk factor for colonization by multiresistant Acinetobacter spp and carbapenem-resistant Pseudomonas aeruginosa in an intensive care unit, Clinics, São Paulo, 2013; 68(8): 1128-1133.

11. DERELI N, et al. Três anos de avaliação das taxas de infecção nosocomial em UTI. Revista Brasileira de Anestesiologia, 2013; 63:1.

12. DOERN GV, et al. A Comprehensive Update on the Problem of Blood Culture Contamination and a Discussion of Methods for Addressing the Problem. Clinical Microbiology Reviews, 2019; 33(1):9-19

13. FIGUEIREDO ML, D'INNOCENZO M. Eventos adversos relacionados às práticas assistenciais: uma revisão integrativa. Revista electrónica trimestral de enfermería, 2017; 47.

14. DALBEN MF, et al. Colonization pressure as a risk factor for colonization by multiresistant Acinetobacter spp and carbape-nem-resistant Pseudomonas aeruginosa in an inten-sive care unit. Clinics, 2013; 68(8): 1128-1133.

15. HESPANHOL LAB, et al. Infecção relacionada à Assistência à Saúde em Unidade de Terapia Intensiva Adulto. Revista electrónica trimestral de enfermería, 2019; 53.

16. LO E, et al. Strategies to Prevent Catheter-Associated Urinary Tract Infections in Acute Care Hospitals. Infection Control \& Hospital Epidemiology, 2008; 29: 41-50.

17. MACHADO MH, et al. O Mercado de trabalho em saúde no Brasil: estrutura e conjuntura. Revista Brasileira de Enfermagem, 1993; 46:2.

18. MODESTO EN, FERREIRA JNM. Carga microbiana presente em jalecos de profissionais de saúde. Revista Eletrônica Acervo Saúde, 2019; $11: 6$.

19. MOREIRA JB, SOUZA ICS. Complicações mais comuns em pacientes internados em terapia intensivas. Revista Científica Univiçosa, 2016; 8:1.

20. OXFORD CENTRE FOR EVIDENCE-BASED MEDICINE. Níveis de Evidência Científica, 2014.

21. PARK WB, et al. Educational intervention as an effective step for reducing blood culture contamination: a prospective cohort study, Journal of Hospital Infection, 2015; 91(2): 111-116.

22. Prevenção de infecções Adquiridas no hospital: guia rápido. Instituto Nacional de Saúde Dr. Ricardo Jorge, 2011.

23. REIS LM, et al. Avaliação da atividade antimicrobiana de antissépticos e desinfetantes utilizados em um serviço público de saúde. Revista brasileira de enfermagem. Brasília, 2011.

24. RESENDE DS, et al. Redução de infecções de corrente sanguínea associadas ao cateter, após procedimentos em neonatos admitidos em uma unidade de teapia intensiva de um hospital universitário no Brasil, Revista da Sociedade Brasileira de Medicina Tropical, 2011, 44(6): 731-734.

25. RIEDEL S, CARROLL KC. Blood cultures: Key elements for best practices and future directionsJournal of Infection and ChemotherapyJapanese Society for Cancer Chemotherapy, 2010.

26. ROCHA IV, et al. Resistência de bactérias isoladas em equipamentos em unidade de terapia intensiva. Escola Paulista de Enfermagem. São Paulo, 2015.

27. SAMPAIO CPS, et al. Principais bactérias causadoras de infecção hospitalar. EFDeportes.com: Revista Digital, vol. 18, n. 182. Buenos Aires, 2013.

28. SANTOS A, et al. Distribuição, evolução e produção científica dos grupos de pesquisa em atividade física e saúde do Brasil. Revista Brasileira de Atividade Física e Saúde. Pelótas, ago. 2012.

29. SANTOS GC, et al. Incidência e fatores de risco de infecção de sítio cirúrgico: revisão integrativa. Itinerarius Reflectionis, vol. 11, n. 1. Minas Gerais, 2015.

30. SECRETARIA DE SAÚDE DO DISTRITO FEDERAL. Análise da resistência microbiana em infecções primárias de corrente sanguínea confirmadas laboratorialmente associadas a cateter venoso central, em unidades de terapia intensiva do Distrito Federal: relatório GRS № 5/2017. Brasilia: Governo do Distrito Federal, 2017.

31. SIDONE OJG, et al. A ciência nas regiões brasileiras: evolução da produção e das redes de colaboração científica. Transinformação, vol. 28, n. 1. Campinas, 2016.

32. SOUZA ES, et al. Mortalidade e risco associado a infecção relacionada à assistência à saúde. Texto contexto enfermagem. Florianópolis, 2015.

33. TURRINI RNT. Infecção hospitalar e mortalidade. Revista da Escola de Enfermagem da USP, vol. 36, n. 2. São Paulo, 2002. 